\title{
Tuberculosis exposure, infection and disease in children: a systematic diagnostic approach
}

\author{
Claudia L. Roya-Pabon ${ }^{1,2}$ and Carlos M. Perez-Velez $2,3,4,5^{*}$
}

\begin{abstract}
The accurate diagnosis of tuberculosis (TB) in children remains challenging. A myriad of common childhood diseases can present with similar symptoms and signs, and differentiating between exposure and infection, as well as infection and disease can be problematic. The paucibacillary nature of childhood TB complicates bacteriological confirmation and specimen collection is difficult. In most instances intrathoracic TB remains a clinical diagnosis. TB infection and disease represent a dynamic continuum from TB exposure with/without infection, to subclinical/ incipient disease, to non-severe and severe disease. The clinical spectrum of intrathoracic TB in children is broad, and the classification of clinical, radiological, endoscopic, and laboratory findings into recognized clinical syndromes allows a more refined diagnostic approach in order to minimize both under- and over-diagnosis. Bacteriological confirmation can be improved significantly by collecting multiple, high-quality specimens from the most appropriate source. Mycobacterial testing should include traditional smear microscopy and culture, as well as nucleic acid amplification testing. A systematic approach to the child with recent exposure to TB, or with clinical and radiological findings compatible with this diagnosis, should allow pragmatic classification as TB exposure, infection, or disease to facilitate timely and appropriate management. It is important to also assess risk factors for TB disease progression and to undertake follow-up evaluations to monitor treatment response and ongoing evidence supporting a $\mathrm{TB}$, or alternative, diagnosis.
\end{abstract}

Keywords: Latent tuberculosis, Algorithm, Diagnostic techniques and procedures, Specimen handling, Risk factors

\section{Background}

Diagnosing tuberculosis (TB) in children is challenging (Table 1) [1] and often it is only considered after the child has failed various therapeutic trials for other disorders. Even with intensive specimen collection and optimal molecular and culture-based diagnostics, most children with non-severe pulmonary TB are not confirmed bacteriologically, despite having an exposure history, immunebased confirmation of infection and clinical features consistent with this diagnosis [2]. Nonetheless, with currently available tools, it is possible to make an accurate clinical diagnosis of intrathoracic TB in most diseased children. This review presents a systematic approach to diagnosing intrathoracic TB in children.

\footnotetext{
*Correspondence: CMPerezVelez@Gmail.com

${ }^{2}$ Grupo Tuberculosis Valle-Colorado (GTVC), Medellin, Antioquia, Colombia

${ }^{3}$ Tuberculosis Clinic, Pima County Health Department, Tucson, AZ, USA

Full list of author information is available at the end of the article
}

\section{Continuum of TB states}

Although much remains unknown about its pathophysiology, TB studies characterized a dynamic continuum of various states that include exposure, infection, subclinical or incipient disease, non-severe and severe disease states (Fig. 1) [3, 4]. Generally, this continuum correlates with bacterial burden [5]. As the archetypical human pathogen, Mycobacterium tuberculosis establishes a sustained but "delicately balanced" host-pathogen relationship [6]. These TB states depend upon various host (e.g. immunological competence), pathogen (e.g. strain virulence), and environmental (e.g. intensity of exposure) factors. The clinical outcome of infection will thus be either self-cure, latency or disease [7]. Understanding that TB is a continuum of states-and not a dichotomy of infection or disease-has important implications for managing children in whom latent or active TB often cannot be confirmed. 
Table 1 Challenges in diagnosing TB exposure, infection and disease in children

\begin{tabular}{|c|c|c|c|}
\hline Disease state & Main challenges & Current status \& limitations & Recent advances \& future prospects \\
\hline \multirow[t]{2}{*}{ Infection } & $\begin{array}{l}\text { Differentiating between } \\
\text { TB exposure (without } \\
\text { infection), and TB } \\
\text { infection }\end{array}$ & $\begin{array}{l}\text { Current immune-based tests (TST and IGRAs) } \\
\text { may not convert to positive until 2-10 weeks } \\
\text { after acquiring } M \text {. tb infection }\end{array}$ & $\begin{array}{l}\text { Mycobacteria-specific cytokine biomarkers - } \\
\text { alone or in combination (i.e., biosignatures) - } \\
\text { may distinguish between TB exposure } \\
\text { (without infection), and TB infection [90] }\end{array}$ \\
\hline & $\begin{array}{l}\text { Differentiating between } \\
\text { infection and subclinical } \\
\text { disease }\end{array}$ & $\begin{array}{l}\text { Chest radiography is the first-line imaging } \\
\text { modality, but may not reveal abnormalities } \\
\text { consistent with TB disease in all cases - } \\
\text { especially those in early states of the }\end{array}$ & $\begin{array}{l}\text { Chest } \mathrm{CT}, \mathrm{MRI} \text {, and PET [91] scan may } \\
\text { reveal findings consistent with TB disease } \\
\text { before symptoms develop }\end{array}$ \\
\hline
\end{tabular}

Disease Detection of TB disease Currently available immune-based tests (TST and of drug resistance and IGRAs) do not differentiate between infection and disease

Currently available tests (e.g. NAATs; culture) for bacteriological confirmation have limited sensitivity for detecting M. tb in young children with paucibacillary disease-especially in early states of the continuum of TB

Specimen collection for bacteriological confirmation currently consists of serial sampling of three gastric aspirates/lavages or induced sputa and requires trained personnel and facilities with airborne infection control

Monitoring response to treatment
Mycobacterial culture is only useful in those children who had positive cultures at time of diagnosis (minority of cases).

Mycobacteria-specific cytokine biomarkers - alone or in combination - may distinguish between TB infection and TB disease [90]

- Xpert MTB/RIF UItra (Cepheid): next generation, ultrasensitive NAAT for detection of both M. tb \& rifamycin resistance; in vitro study demonstrated sensitivity comparable to culture $[92,93]$.

- GeneXpert Omni (Cepheid): single-cartridge battery-operated platform that is portable/mobile; study pending [93]

- Xpert XDR NAAT (Cepheid): study anticipated in 2018 [93]

Strategies consisting of "intensive" collection of combinations of various specimens (e.g., nasopharyngeal aspirates; string tests; stool; fine needle aspirate of diseased lymph node) that have similar or superior bacteriological yield, require less training, and may be carried out as an outpatient over $1-2$ days

Cytokine biomarkers and biosignatures (possibly including IFN- $\gamma$, TNF-a, IL-2, IL-6, IL-10 and/or IL-12) [94, 95]

18 F-FDG PET/CT is sensitive for the detection of TB disease (in different states of the continuum) and for monitoring response to treatment [91]

$C T$ computed tomography, IGRA interferon-gamma release assay, MRI magnetic resonance imaging, $M$. tb: Mycobacterium tuberculosis, NAAT nucleic acid amplification test, $P C R$ polymerase chain reaction, $P E T$ positron emission tomography, TB tuberculosis, TST tuberculin skin test, XDR extensively drug-resistant

\section{Clinical spectrum of disease}

Once infected with $M$. tuberculosis, young children (aged $<5$ years) are at greater risk than adults of progressing to disease, including its most severe forms. This depends on the child's susceptibility, which is highest during the first years of life, probably from immunological immaturity. Without Bacille CalmetteGuerin (BCG) vaccination, approximately 30\% of infected infants $(<1$ year old) will progress to intrathoracic $\mathrm{TB}$, and $10-20 \%$ will develop disseminated disease. In children aged 1-2 years, the risk of progressing to intrathoracic TB is $10-20$ and $2-5 \%$ for disseminated disease. These risks decline slowly until around 10 years of age when adult-type disease starts to emerge $[8,9]$. Thus, early diagnosis is important, especially in infants and young children who are at greatest risk of rapid disease development [8] and clinicians should consider the full clinical spectrum of intrathoracic syndromes [10].

\section{Clinical classification of tuberculosis}

Classifying intrathoracic TB by immunopathogenesis (Table 2) assists understanding how each possible "state" in the continuum is managed [11]. For example, a child with a history of $\mathrm{TB}$ exposure can have the features of subclinical disease [12] outlined in Table 2, which in some hierarchical diagnostic classification systems corresponds to "possible" intrathoracic TB. A typical example is that of a young child with isolated uncomplicated hilar lymphadenopathy [13]. Such a child may not meet sufficient criteria to be clinically diagnosed with "probable" intrathoracic TB given their lack of symptoms and physical signs, [14] and consequently may not receive treatment for tuberculosis disease or infection. Whether this intermediate state will progress to clinically manifest disease or be contained as latent infection is dependent on the child's level of immunocompetence. In those with risk factors for progression to $\mathrm{TB}$ disease, treatment is recommended. Children with disease can be further 


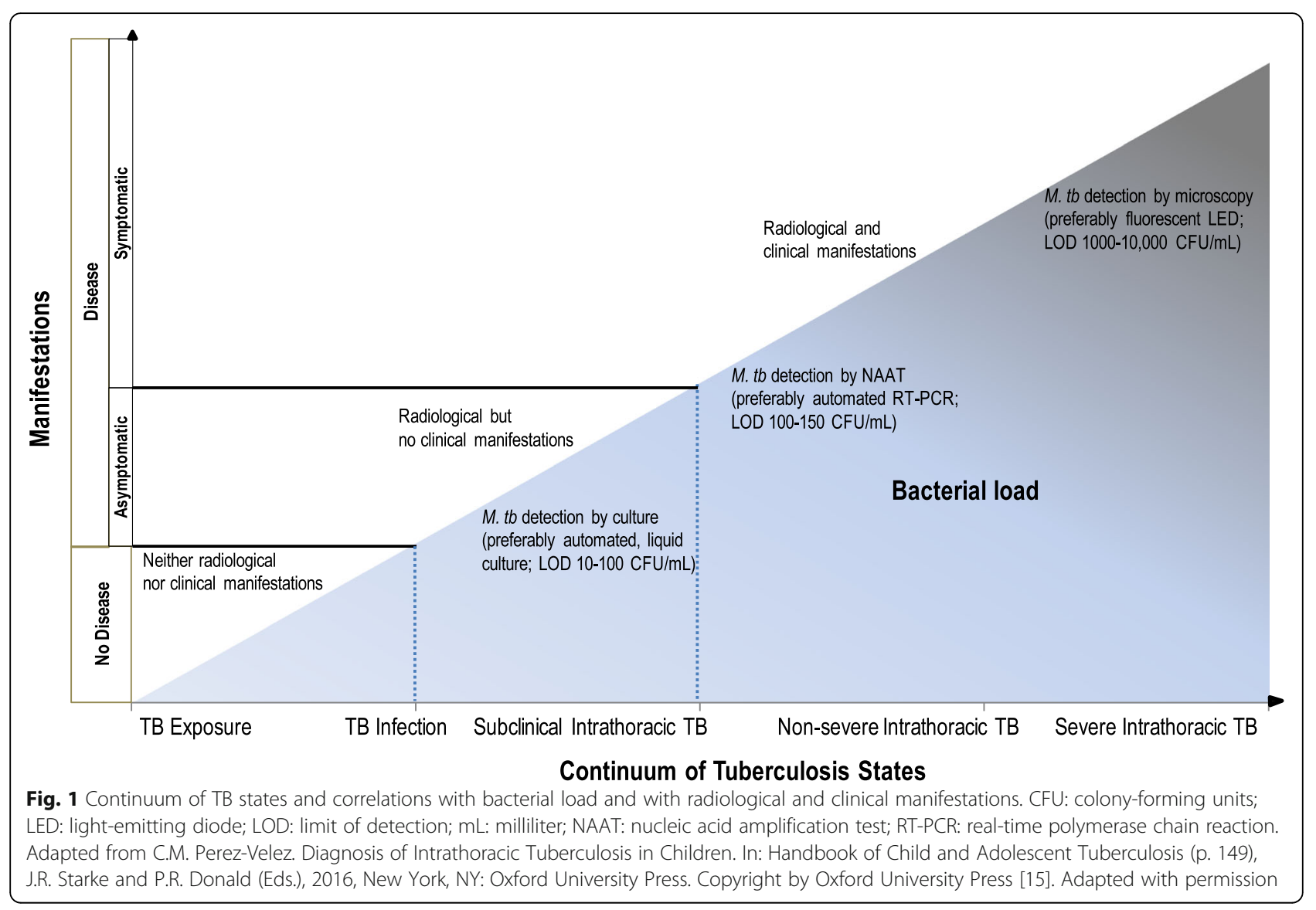

Table 2 Clinical classification of intrathoracic TB based on immunopathogenesis

\begin{tabular}{|c|c|c|c|c|c|}
\hline $\begin{array}{l}\text { Clinical } \\
\text { classification }\end{array}$ & Immunopathogenesis & TST/IGRA & Imaging & $\begin{array}{l}\text { Clinical } \\
\text { manifestations }\end{array}$ & $\begin{array}{l}\text { Myco-bacterial } \\
\text { detection }\end{array}$ \\
\hline TB exposure & $\begin{array}{l}\text { Self-cure (infection eliminated by } \\
\text { innate immune response; no } \\
\text { T-cell activation) }\end{array}$ & Negative & Normal & None & Negative \\
\hline Latent TB infection & $\begin{array}{l}\text { Quiescent infection (non-replicating } \\
\text { bacteria persisting with very low } \\
\text { metabolic activity; infection } \\
\text { well-contained) }\end{array}$ & Positive & $\begin{array}{l}\text { - Calcified non-enlarged } \\
\text { regional lymph nodes } \\
\text { - Calcified lung nodules } \\
\text { - Pleural thickening }\end{array}$ & None & Negative \\
\hline Subclinical TB & $\begin{array}{l}\text { Incipient disease (replicating bacteria } \\
\text { that are metabolically active; } \\
\text { infection contained) }\end{array}$ & $\begin{array}{l}\text { Usually } \\
\text { positive }\end{array}$ & $\begin{array}{l}\text { - Uncomplicated hilar/ } \\
\text { mediastinal lymphadenopathy } \\
\text { - Non-calcified lung nodules } \\
\text { - Uncomplicated pleural } \\
\text { effusion }\end{array}$ & None & $\begin{array}{l}\text { Usually negative } \\
\text { (may be transiently } \\
\text { positive) }\end{array}$ \\
\hline Non-severe TB & $\begin{array}{l}\text { Mild-to-moderate disease (replicating } \\
\text { bacteria that are metabolically active; } \\
\text { infection only partially contained) }\end{array}$ & $\begin{array}{l}\text { Usually } \\
\text { positive }\end{array}$ & $\begin{array}{l}\text { - Uncomplicated hilar/ } \\
\text { mediastinal lymphadenopathy } \\
\text { - Non-calcified lung nodules } \\
\text { - Uncomplicated pleural } \\
\text { effusion }\end{array}$ & Mild-to-moderate & $\begin{array}{l}\text { Positive cultures } \\
\text { (10-30\% of cases) }\end{array}$ \\
\hline Severe TB & $\begin{array}{l}\text { Severe disease (replicating bacteria } \\
\text { that are metabolically active; infection } \\
\text { not contained) }\end{array}$ & $\begin{array}{l}\text { Usually } \\
\text { positive }\end{array}$ & $\begin{array}{l}\text { See spectrum of } \\
\text { disease (Fig. 2) }\end{array}$ & Severe & $\begin{array}{l}\text { Positive cultures } \\
\text { (30-70\% of cases) }\end{array}$ \\
\hline
\end{tabular}

Adapted from C.M. Perez-Velez. Diagnosis of Intrathoracic Tuberculosis in Children. In: Handbook of Child and Adolescent Tuberculosis (p. 149), J.R. Starke and P.R. Donald (Eds.), 2016, New York, NY: Oxford University Press. Copyright by Oxford University Press [15]. Adapted with permission IGRA Interferon-gamma release assay, PCR polymerase chain reaction, TB tuberculosis, TST tuberculin skin test 
classified as severe or non-severe, depending on whether or not infection is contained and on the presence and extent of complications.

\section{Systematic diagnostic approach}

As it is impossible to achieve bacteriological confirmation in many childhood TB cases, systematically identifying findings suggestive of TB can allow for its clinical diagnosis. Excluding other differential diagnoses and observing a positive therapeutic response increases the probability of $\mathrm{TB}$ being the correct diagnosis. The following systematic approach to diagnosing $\mathrm{TB}$ in children consists of (i) identifying findings suggesting TB disease; (ii) identifying findings supportive of TB as the etiology; (iii) screening for risk factors for progression to disease; and (iv) follow-up evaluations to further support or exclude TB as the etiology (Table 3) [15].

Table 3 Systematic approach to the diagnosis of intrathoracic TB in children

Step 1: Identify findings suggestive of TB disease

- Clinical evaluation: history \& physical exam

- Radiological imaging: chest radiography; computed tomography; ultrasonography

- Laboratory studies: composite measures (cell count and chemistry) of body fluids (e.g., pleural fluid)

- Endoscopic studies: bronchoscopy

Step 2: Identifying findings supportive of TB as the etiology

- TB exposure history

- Immune-based tests: TST; IGRA

- Biochemical markers: ADA in body fluids (e.g., pleural fluid; pericardial fluid)

- Mycobacterial detection: smear microscopy; NAAT; culture; antigen test (in HIV-infected adolescents, lateral flow lipoarabinomannan in urine with $C D 4<100)$

- Histopathological \& cytopathological studies

- Excluding other differential diagnoses

Step 3: Screen for risk factors for progression to TB disease

- Age groups (e.g. immunological immaturity of infancy)

- Immunocompromising conditions (e.g., HIV infection)

- Immunosuppressive medications (e.g., TNF-a) antagonists

- Contained TB infection-disease (e.g., noncalcified fibronodular lesions, especially apical, on chest imaging

- Environment (e.g., continued exposure)

Step 4: Follow-up evaluation to support or exclude TB as the etiology

Adapted from C.M. Perez-Velez. Diagnosis of Intrathoracic Tuberculosis in Children. In: Handbook of Child and Adolescent Tuberculosis (p. 149), J.R. Starke and P.R. Donald (Eds.), 2016, New York, NY: Oxford University Press. Copyright by Oxford University Press [15]. Adapted with permission $A D A$ adenosine deaminase, $C D 4$ cluster of differentiation 4, HIV human immunodeficiency virus, IGRA interferon gamma release assay, NAAT nucleic acid amplification test, TB tuberculosis, TNF- $\alpha$ tumor necrosis factor alpha, TST tuberculin skin test
STEP 1: Identify findings suggestive of TB disease

Each intrathoracic clinical syndrome of TB disease has its own constellation of clinical, radiological, laboratory, and endoscopic (if indicated) findings, although many are shared by more than one clinical syndrome. Furthermore, miliary lung disease may also involve potentially any organ system (Additional file 1: Textbox 1). Most clinical manifestations of intrathoracic TB result from the overall balance of beneficial and harmful immune responses to $M$. tuberculosis and a severe inflammatory reaction can be triggered by a relatively low burden of organisms. There are no clinical features pathognomonic of intrathoracic TB, but combinations of symptoms and physical signs with certain temporal patterns can help differentiate it from other etiologies that might mimic this disorder.

\section{Clinical evaluation}

Pulmonary TB is frequently associated with intrathoracic lymphadenopathy, and sometimes with pleural or pericardial disease, and therefore "intrathoracic TB" is the preferred term in children. Localized symptoms and physical signs depend on which intrathoracic organs are involved, while non-localized symptoms and signs are independent of the organ-specific clinical syndrome. Symptoms and physical signs that are well-defined have higher specificity. However, in children who are immunocompromised (e.g. less than three years of age with immunological immaturity), HIV-infected, or severely malnourished, these symptoms and signs have lower sensitivity and specificity [16].

Systemic symptoms and signs may appear early or late in the disease course [17]. Daily fever is characteristically $>38.0^{\circ} \mathrm{C}$, intermittent or persistent throughout the day, and usually lasts $>1$ week. Night sweats are uncommon, subjective and nonspecific, and are significant only when they drench the child's clothes and bedding. Chills and rigors are rare, except in disseminated disease. Anorexia and associated wasting or failure to thrive during the past 3-6 months, or having lost $>10 \%$ of body weight over any interval of time, are sensitive-albeit nonspecific-signs in most TB clinical syndromes in young children [16]. The immunocompromised state from severe under-nutrition can increase the risk for a paradoxical reaction when they receive $\mathrm{TB}$ treatment and nutritional rehabilitation [18]. Fatigue, asthenia, and malaise may manifest in young children as listlessness (e.g. decreased playfulness) and in infants as apathy (e.g. less interactive with caregivers) and should be persistent and not attributable to other causes.

Peripheral lymphadenopathy from TB typically consists of a unilateral, enlarged, non-painful, rubbery lymph node, sometimes becoming fluctuant, with or 
without spontaneous drainage forming a sinus tract [19]. Respiratory symptoms and signs depend on the site, and degree of involvement (e.g. of airway obstruction). The cough is usually unremitting for $>2$ weeks and may be "dry" or "wet". When the airway is compressed by an enlarged lymph node, there may be persistent cough, wheezing or stridor that does not improve with inhaled bronchodilators (Additional file 1: Table S1). Characterizing the temporal pattern (including the onset, progression and duration) of symptoms helps clinicians to identify cases with likely intrathoracic TB.

\section{Radiological Imaging}

Chest imaging-including radiography, computed tomography (CT), and ultrasonography-is one of the most useful diagnostic modalities for detecting intrathoracic TB. The spectrum of radiological abnormalities in children is very broad, and none are sufficiently specific to confirm the diagnosis [20, 21]. Nonetheless, certain patterns and signs are highly suggestive, especially when accompanied by clinical features and supportive findings (e.g. recent TB exposure, and positive T-cell-based test). Recognizing such radiological patterns (Fig. 2) helps narrow the differential diagnosis (Additional file 1: Table S3). Chest radiography-including both frontal and lateral projections-is the first-line imaging modality when intrathoracic TB is suspected. The lateral projection helps detect retrocarinal, subcarinal, and superimposed hilar lymphadenopathy, especially in infants where the thymus may obscure enlarged nodes on the frontal view [22, 23]. Additionally, CT scans may detect abnormalities suggestive of intrathoracic TB in a child suspected of having complicated intrathoracic lymph node or pleural disease, endobronchial lesions, bronchiectasis, or cavities that are not well revealed on plain radiography [24, 25]. Finally, chest ultrasonography is useful for evaluating mediastinal lymphadenopathy and pericardial effusions. Also, it is the preferred imaging modality in differentiating loculated from free-flowing pleural effusions [26, 27].

\section{Endoscopy}

Bronchoscopy may be useful in diagnosing and managing cases with tracheobronchial disease [28]. However, it is not routinely indicated for evaluating all intrathoracic $\mathrm{TB}$ clinical syndromes.

\section{Laboratory tests}

While non-microbiological laboratory tests results can suggest TB disease, they are not confirmatory of this diagnosis. The cell count and chemistry of body fluids, such as pleural or pericardial fluids, can raise the possibility of TB when the composite results are consistent with the disease. However, other diseases, including non-tuberculous mycobacterial species and fungal infections, can also provide similar results. The following features suggest TB: cell count predominantly lymphocytic (may be neutrophilic within the first few days); elevated protein level $(>30 \mathrm{~g} / \mathrm{L}$; protein/serum protein ratio $>0.5)$; elevated $\mathrm{LDH}(>200 \mathrm{IU} / \mathrm{L} ; \mathrm{LDH} /$ serum $\mathrm{LDH}$ ratio $>0.6$ ); glucose $3.0-5.5 \mathrm{mmol} / \mathrm{L}$ (usually lower in effusions due to pyogenic bacteria or rheumatoid arthritis); normal lipids (elevated in chylous effusions). The most common findings on full blood count are mild anemia, neutrophilia, and monocytosis, but these abnormalities are found just as frequently in other respiratory infections [29]. Erythrocyte sedimentation rate may be normal or elevated (e.g. $>100 \mathrm{~mm} / \mathrm{h}$ ), but is nonspecific, as are C-reactive protein and procalcitonin [30,31].

\section{STEP 2: Identify findings supportive of TB as the etiology}

The positive predictive value of each of the following types of findings depends on the local TB prevalence.

\section{Exposure history}

Children are usually infected following exposure to someone with pulmonary TB whose sputum is positive by microscopy or culture, who is actively coughing, and with whom they share the same space (e.g. household, daycare centers, schools, healthcare facilities, refugee camps). In children aged $<5$ years, the source case is most often from the same household, and the infection usually acquired within the past year. As children become exposed to the community outside the household, their risk of acquiring infection from this source increases and inquiring about confirmed or suspected $\mathrm{TB}$ contacts and knowledge of the local TB epidemiology becomes more pertinent [32].

\section{Immune-based testing}

Memory T-cells, detected by a tuberculin skin test (TST) and current $M$. tuberculosis interferon-gamma release assays (IGRAs) measure lasting TB immune responses and can represent any of the following: active TB disease, previous TB disease, latent TB infection, recent or remote TB exposure, or exposure to environmental nontuberculous mycobacteria (NTM; e.g. M. kansasii, M. szulgai, M. marinum) that may have cross-reactivity. Neither IGRAs nor TST can distinguish latent from active TB [33]. Table 4 provides a comparison of currently approved T-cell-based tests including TST, and IGRAs specific for $M$. tuberculosis, such as the ELISPOT-based T-SPOT TB (Oxford Immunotec) and the ELISA-based QuantiFERON (QFT) Gold In-Tube and QFT Gold Plus (Qiagen). TST and IGRAs are complementary, so using both increases sensitivity [42].

A T-cell-based test may be positive in TB infection as well as TB disease. When positive in a child with a 
a

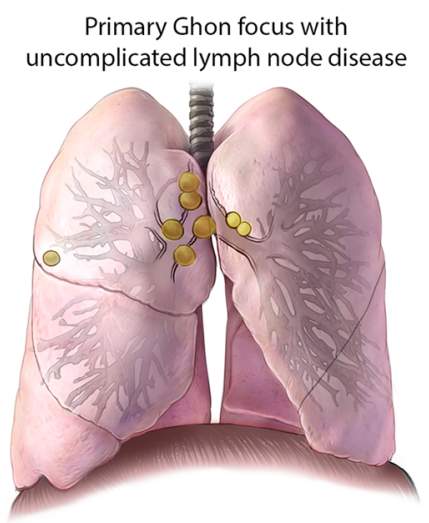

C

Complicated lymph node disease

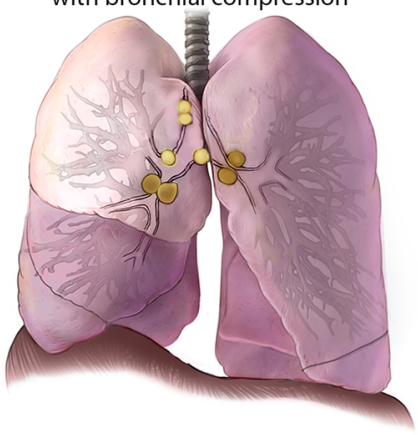

e

Complicated lymph node disease
with expansile lobar pneumonia

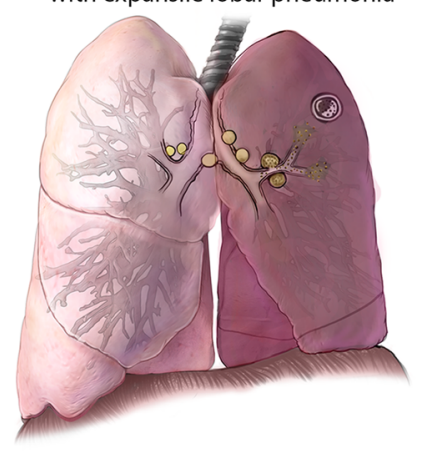

b

Progressive Ghon focus with uncomplicated lymph node disease

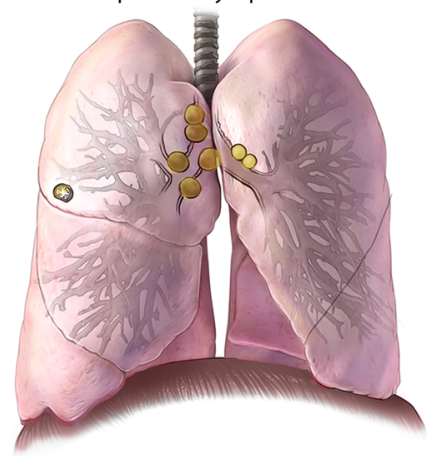

d Complicated lymph node disease

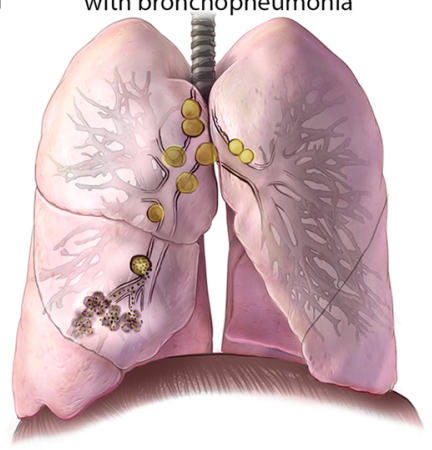

f

Miliary (disseminated) disease

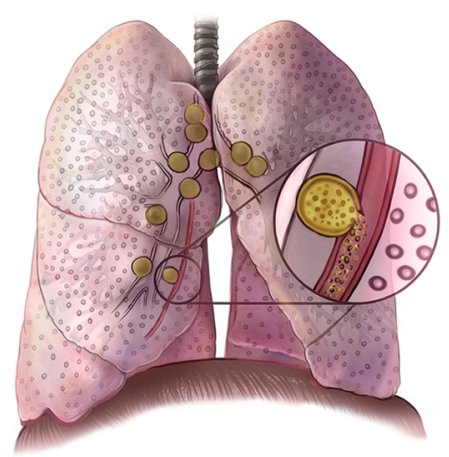

Fig. 2 Illustrations of radiological patterns caused by intrathoracic TB in children. Panel a. Primary Ghon focus with uncomplicated lymph node disease. Hilar and mediastinal lymphadenopathy associated with an ipsilateral peripheral nodule, or "Ghon focus" (right lung); these nodules are often subpleural with an overlying pleural reaction. Panel b. Progressive Ghon focus with uncomplicated lymph node disease. A Ghon focus with cavitation (right lung), which is seen almost exclusively in infants and immunocompromised children; other elements of the Ghon complex are also visible. Panel c. Complicated lymph node disease with bronchial compression. Enlarged lymph nodes compressing the airway, causing either complete obstruction with lobar collapse (right middle and lower lobes), or partial obstruction with a ball-valve effect leading to hyperinflation (left upper and lower lobes). Panel d. Complicated lymph node disease with bronchopneumonia. Necrotic lymph nodes erupting into bronchus intermedius, with endobronchial spread and patchy consolidation of the middle lobe (right lung). Panel e. Complicated lymph node disease with expansile lobar pneumonia. Necrotic lymph nodes that compress and obstruct the left upper lobe bronchus and may infiltrate a phrenic nerve, causing hemidiaphragmatic palsy (left-sided); endobronchial spread causes dense consolidation of the entire lobe (left upper lobe), with displacement of the trachea and fissures and the formation of focal cavities. Panel f. Miliary (disseminated) disease. Diffuse micronodules in both lungs, which may result from lymphohematogenous spread after recent primary infection or from infiltrating a necrotic lymph node or lung lesion into a blood vessel, leading to hematogenous spread 

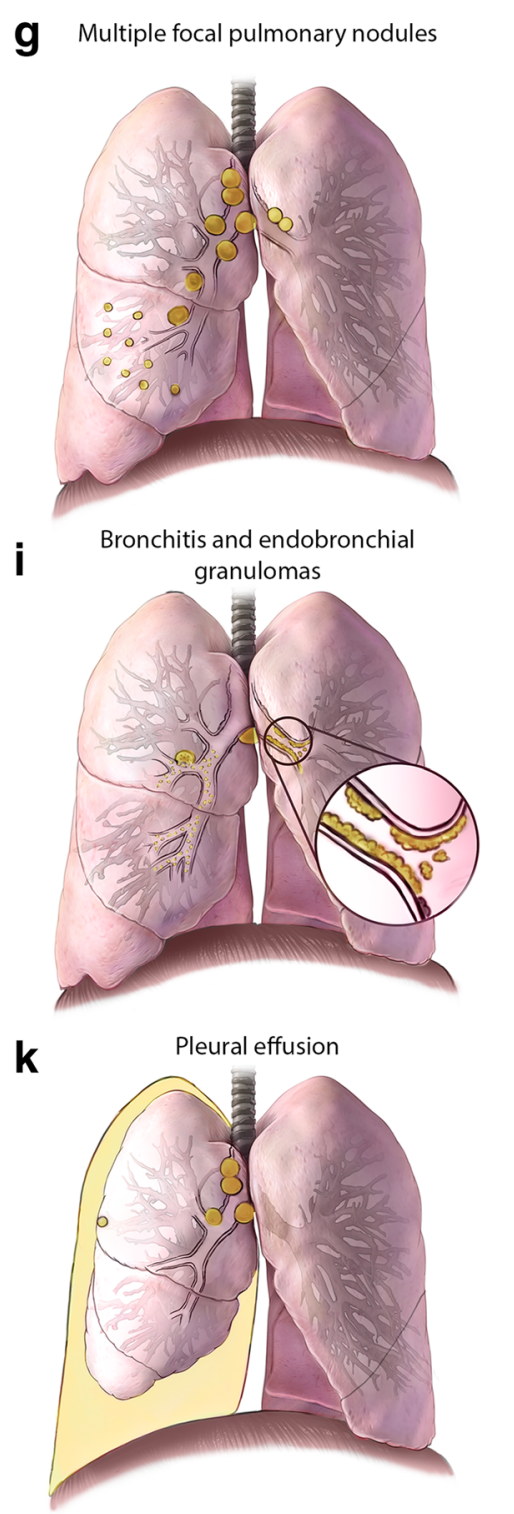
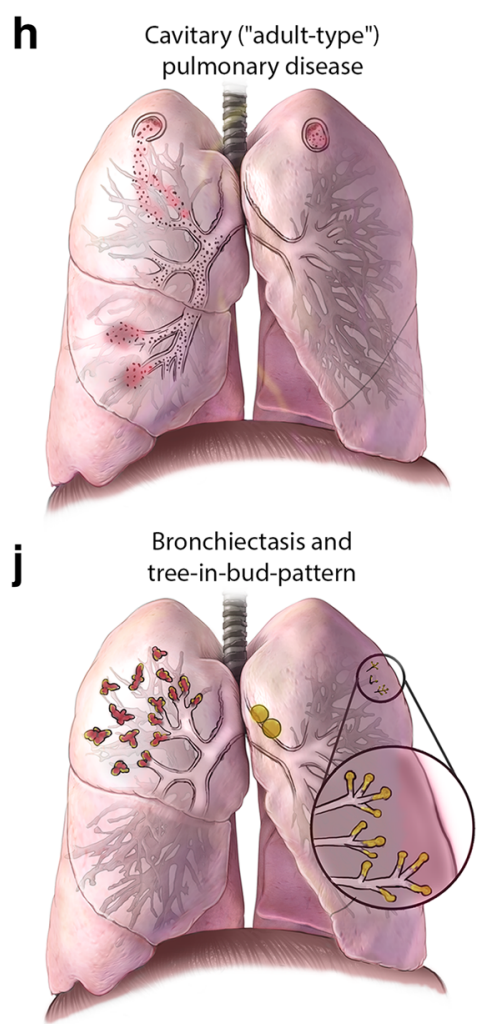

I

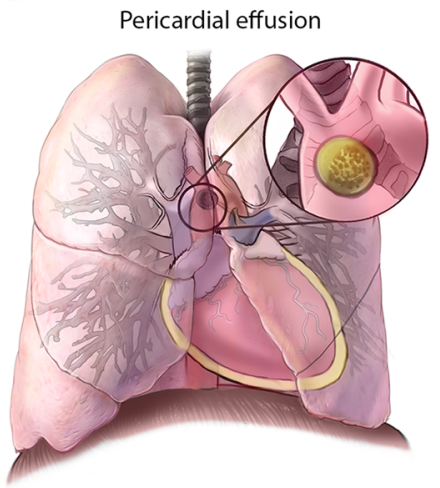

Fig. 2 (continued) Panel g. Multiple focal pulmonary nodules. Multiple focal pulmonary nodules involving the right middle lobe with enlargement of regional lymph nodes (right lung). Panel h. Cavitary ("adult-type") pulmonary disease. Cavity formation in both upper lobes, with endobronchial spread to the right middle lobe. Nodules or cavities in apical lung segments are typical of adult-type disease and are pathologically distinct from the other cavities shown. Panel i. Bronchitis and endobronchial granulomas. Inflammation of the mucosa of main stem bronchus with purulent secretions (left lung), and a necrotic lymph node that has eroded into the right middle lobe bronchus leading to endobronchial spread and subsequent development of endobronchial granulomas extending proximally to the bronchus intermedius and main stem bronchus, and distally to the lower lobe bronchus (right lung). These findings are best visualized by bronchoscopy. Panel $\mathbf{j}$. Bronchiectasis and tree-in-bud-pattern. Bronchiectasis that extensively involves the upper lobe (right lung), and shows tree-in-bud pattern observable on $\subset$ scans - reflecting dilated centrilobular bronchioles with mucoid impaction - involving the upper lobe (left lung). Panel k. Pleural effusion. A pleural effusion that is usually indicative of recent primary infection, with a hypersensitivity response to tuberculoprotein leaking from a subpleural Ghon focus (often not visible) into the pleural cavity; in rare cases this effusion may also result from a chylothorax. Panel I. Pericardial effusion. A pericardial effusion that occurs when tuberculoprotein leaks from a necrotic subcarinal lymph node (shown in "close-up" window) into the pericardial space; it may also occur after hematogenous spread. Conceptualization and original sketches by C.L. Roya-Pabon, MD; finished artwork by Mesa Schumacher, MA (used with permission). Adapted from C.M. Perez-Velez. Diagnosis of Intrathoracic Tuberculosis in Children. In: Handbook of Child and Adolescent Tuberculosis (p. 154-155), J.R. Starke and P.R. Donald (Eds.), 2016, New York, NY: Oxford University Press. Copyright by Oxford University Press [15]. Adapted with permission 
Table 4 Comparison of T cell-based tests for TB infection

\begin{tabular}{|c|c|c|c|}
\hline Characteristic & Tuberculin Skin Test & QuantiFERON-TB ${ }^{\oplus *}$ & T-SPOT-TB ${ }^{\otimes * *}$ \\
\hline Time to results & $48-72 \mathrm{~h}$ & $24-36 \mathrm{~h}$ & $36-48 \mathrm{~h}$ \\
\hline Complexity & Low & Moderate & High \\
\hline TB antigens & $\begin{array}{l}\text { PPD-tuberculin } \\
\text { (not specific to M. tb.) }\end{array}$ & ESAT-6; CFP-10; TB-7.7 & ESAT-6; CFP-10 \\
\hline Measurement & $\begin{array}{l}\text { Skin induration after } \\
\text { in vivo stimulation }\end{array}$ & $\begin{array}{l}\text { ELISA-based measurement of } \\
\text { IFN- } \gamma \text { production by T-cells } \\
\text { after in vitro stimulation }\end{array}$ & $\begin{array}{l}\text { ELISPOT-based measurement } \\
\text { of IFN- } \gamma \text {-producing T-cells } \\
\text { (spots) after in vitro stimulation }\end{array}$ \\
\hline $\begin{array}{l}\text { Minimum number of } \\
\text { visits to complete testing }\end{array}$ & $\begin{array}{l}2 \text { visits } \\
\text { (within } 48-72 \mathrm{~h} \text { of placement) }\end{array}$ & 1 visit & \\
\hline Sample/Method & $\begin{array}{l}\text { Intradermal injection of } 5 \text { units } \\
\text { of PPD-tuberculin }\end{array}$ & Blood draw & \\
\hline $\begin{array}{l}\text { Reliability/Nariability } \\
\text { of test results }\end{array}$ & $\begin{array}{l}\text { Limited variability with } \\
\text { appropriate training [34] }\end{array}$ & $\begin{array}{l}\text { Significant within-person } \\
\text { variability }[35,36]\end{array}$ & \\
\hline $\begin{array}{l}\text { Cross-reactivity with } \\
\text { BCG vaccine }\end{array}$ & $\begin{array}{l}\text { Yes (particularly if vaccinated } \\
\text { after infancy or repeatedly) } \\
{[37,38]}\end{array}$ & No & \\
\hline NTM cross reaction & Many & $\begin{array}{l}\text { Few (M. kansasii, M. marinum, } \\
\text { M. szulgaii) }\end{array}$ & \\
\hline $\begin{array}{l}\text { Booster effect with } \\
\text { repeated testing }\end{array}$ & Yes & No & \\
\hline Booster effect after prior TST & Yes & $\begin{array}{l}\text { Possible (but likely inconsequential } \\
\text { if blood drawn }<3 \text { days after TST [39] }\end{array}$ & \\
\hline Internal controls & No & Yes & \\
\hline Utility by age & $\begin{array}{l}\text { Less reliable in children under } \\
6 \text {-months of age }\end{array}$ & $\begin{array}{l}\text { Less reliable in children under } \\
5 \text {-years of age }\end{array}$ & \\
\hline $\begin{array}{l}\text { Sensitivity with bacteriologically- } \\
\text { confirmed TB }\end{array}$ & $75-85 \%[40]$ & $80-85 \%[40]$ & \\
\hline $\begin{array}{l}\text { Specificity with bacteriologically- } \\
\text { confirmed TB }\end{array}$ & $\begin{array}{l}95-100 \% \text { [40] } \\
\text { With BCG vaccination 49-65\% [40] }\end{array}$ & $\begin{array}{l}90-95 \% \text { [40] } \\
\text { With BCG vaccination 89-100\% [40] }\end{array}$ & \\
\hline $\begin{array}{l}\text { Sensitivity in HIV-infected } \\
\text { patients }\end{array}$ & $45 \%[36]$ & $\begin{array}{l}\text { Same as TST [36]; T-SPOT.TB slightly } \\
\text { less affected by immunosuppression } \\
\text { than QFT [41] }\end{array}$ & \\
\hline
\end{tabular}

BCG bacille Calmette-Guérin, IGRA interferon-gamma release assay, M. tb Mycobacterium tuberculosis, NTM nontuberculous mycobacteria, PPD purified protein derivative, TB tuberculosis, TST tuberculin skin test

clinical syndrome compatible with $\mathrm{TB}$, a T-cell-based test is supportive of TB as the etiology. However, these tests-regardless of their degree of positivity-cannot distinguish between latent infection and active disease. Determining whether someone has active disease rather than latent infection depends upon findings (e.g. clinical, radiological, laboratory, or endoscopic) consistent with $\mathrm{TB}$ disease being present. Furthermore, in children with immunocompromising conditions the sensitivity of T-cellbased tests is decreased. When negative or indeterminate in the setting of a very recent TB exposure or of suspected TB disease (especially one overwhelming the immune system), it may be useful to repeat the T-cell-based test (e.g. in 8-10 weeks) when immune conversion is complete or effective TB treatment reduced the mycobacterial burden. However, a negative T-cell-based (TST/IGRA) test cannot be used to exclude TB infection or disease [43].

\section{Biochemical markers}

Depending on the cutoff levels used, biochemical markers can have a sensitivity and specificity sufficiently high enough to strongly support TB as the cause of pleural or pericardial effusions. Although most studies have been undertaken in adults, their results should also apply in children. In pleural TB, using $40 \mathrm{U} / \mathrm{L}$ as the cutoff, the sensitivity of adenosine deaminase (ADA) is approximately $90 \%$ and its specificity is around 92\% [44, 45]. In pericardial tuberculosis, the sensitivity and specificity of ADA levels $40 \mathrm{U} / \mathrm{L}$ are approximately 88 and $83 \%$, respectively [30].

\section{Microbiological studies}

In children with an intrathoracic clinical syndrome consistent with TB, microbiological studies should always be 


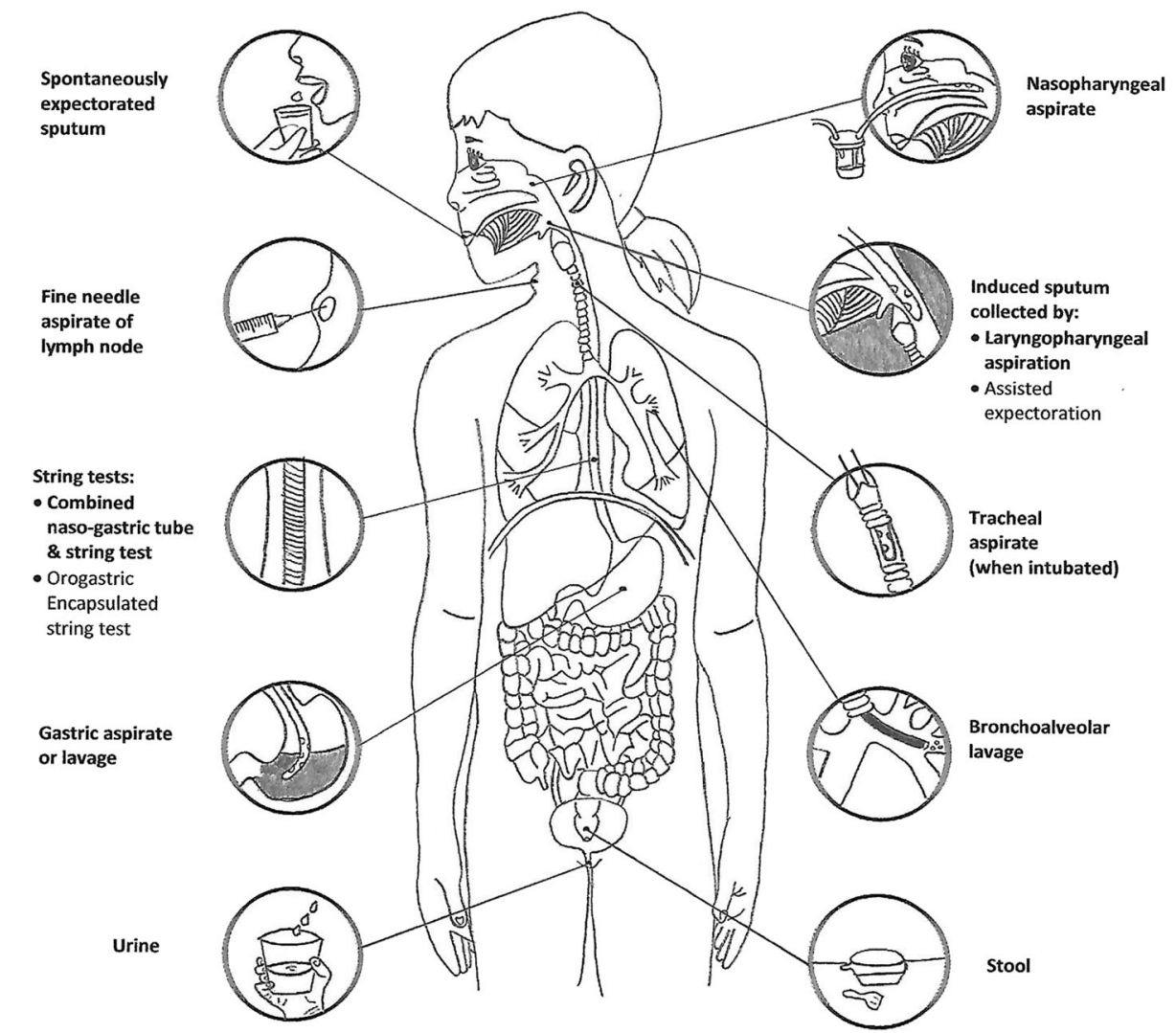

Fig. 3 Specimens for bacteriological confirmation of intrathoracic TB in children. Adapted from C.L. Roya-Pabon. Especímenes Respiratorios para el Diagnóstico Microbiológico de las Infecciones Respiratorias. In: Neumología Pediátrica (p. 179), R. Posada-Saldarriaga (Ed.), 2016, Bogotá, Colombia: Distribuna Editorial. Copyright by Distribuna Ltda. [46]. Adapted with permission

performed as they allow for bacteriological confirmation and for antibiotic susceptibility/resistance testing.

\section{Specimen collection}

M. tuberculosis can be detected from various specimens (Fig. 3). Specimen collection should be performed before TB treatment. The specimen collection strategy should include collecting at least two samples (preferably of different specimen types), ensuring high -quality and -quantity of each sample and considering pooling of samples if necessary [47-50]. Early morning respiratory specimens generally have the best yield. Older children (aged $\geq 10$ years) can usually expectorate sputum of adequate quality and volume, without coaching or assistance (i.e. spontaneously expectorated sputum). Younger children (aged 5-10 years) can usually expectorate with assistance and the very young (aged $<5$ years) are unable to expectorate effectively requiring secretions in the laryngopharynx to be suctioned following sputum induction (i.e. induced sputum collected by laryngopharyngeal aspiration) [51]. The term "laryngopharyngeal aspirate" is recommended as this specimen type is collected from the laryngopharyngeal space, it contains less saliva, and is less contaminated by oral microbiota than respiratory secretions passing through the mouth. [21, 46]. Alternatively, lower respiratory secretions that have reached the nasopharynx can be suctioned (known as "nasopharyngeal aspirate") [51]. Bronchoalveolar lavage should be reserved for children from whom less invasive specimen collection is not attainable, especially as its bacteriological yield is lower than that of serial gastric aspirates $[52,53]$.

Since young children usually swallow their respiratory secretions, these can be collected by gastric aspiration or lavage (gastric aspiration is preferred). These can also be captured in the esophagus using an intra-esophageal, highly-absorbent nylon yarn, employing as a vehicle for its placement either a gelatin capsule (string test) that is swallowed or a nasogastric tube (combined nasogastric-tubeand-string test). In cooperative children (aged $>4$ years) able to swallow the gelatin capsule containing the string, the conventional string test is associated with minimal discomfort. In younger children unable to swallow the capsule, the combined nasogastric-tube-and-string test allows two specimens (one gastric aspirate and one string test) to be collected $[54,55]$. As young children swallow their sputum, stool may also contain $M$. tuberculosis and a 
nucleic acid amplification test (NAAT), such as Xpert MTB/RIF (Cepheid, United States of America), on stool can bacteriologically confirm approximately $45 \%$ of clinically diagnosed cases of pulmonary TB $[56,57]$.

In children with enlarged peripheral lymph nodes (usually cervical), a fine needle aspiration biopsy is the specimen of choice, and should be submitted for: (i) mycobacterial testing, i.e. NAAT (Xpert MTB/RIF has a sensitivity of $\sim 83 \%$ using culture as reference) and culture; and (ii) pathological studies (cytopathology of aspirate; histopathology of biopsied tissue) [58, 59]. Serosal fluids (e.g. pleural and pericardial) should be collected and submitted for biochemical markers, mycobacterial testing, and cytopathological studies. The diagnostic yield of serosal fluids increases as more types of tests performed. Serosal tissue generally has a higher culture yield and so biopsy (e.g. of the pleura or pericardium) may be justified, especially when drug-resistant TB is suspected (allowing susceptibility testing to be undertaken).

\section{Mycobacterial detection}

\section{Acid-fast staining and smear microscopy}

Acid-fast staining and smear microscopy is a rapid and relatively inexpensive test for detecting acid-fast bacilli (AFB). Unfortunately, the sensitivity of smear microscopy varies greatly based on AFB load. For reliable detection, a sample must contain AFB of at least 100010,000 colony-forming units $(\mathrm{CFU}) / \mathrm{mL}$ [60]. This relatively high detection limit, together with the paucibacillary nature of TB disease in children, contributes to the very low sensitivity of smear microscopy.

Acid-fast stains are also not specific for $M$. tuberculosis complex as they cannot differentiate between mycobacterial species. Nonetheless, in a child with a high pre-test probability of having pulmonary $\mathrm{TB}$, a positive result has a high predictive value, and studies using culture as a reference standard report a very high specificity ( 95\%) [61-63]. Microscopy's low sensitivity and inability to differentiate between AFB species (especially relevant for gastric aspirate specimens), means it should not be used as a sole mycobacterial test for detecting $M$. tuberculosis.

\section{Nucleic acid amplification tests or antigen detection}

NAATs are rapid tests that include real-time polymerase chain reaction (RT-PCR) and line probe assays (LPAs) (Additional file 1: Table S2). Recently developed NAATs can also simultaneously detect genes conferring drug resistance, allowing prompt and more appropriate treatment of cases with drug-resistant disease. The fully automated Xpert MTB/RIF test has high sensitivity (pooled estimate 95-96\%) in sputum smear-positive samples using culture as a reference standard, but only moderate sensitivity (pooled estimate 55-62\%) in smear-negative samples [64]. In 2013, the World Health Organization recommended using Xpert MTB/RIF in samples from children, especially those suspected of multidrug-resistant TB or HIV coinfection [64]. Certain LPAs detect M. tuberculosis with/ without drug resistance mutations, as well as common NTM, such as $M$. avium, $M$. intracellulare, and $M$. kansasii. GenoType MTBDRplus (Hain Lifescience, Holland) or Genoscholar NTM + MDRTB $^{\circ}$ (Nipro Europe, Germany) are especially useful for simultaneously detecting isoniazid- and rifampin-resistance in microscopy-positive samples or culture isolates [65-67]. Regarding antigen detection tests the urine lateral flow lipoarabinomannan (LFLAM) assay may be useful in adolescents with advanced HIV disease and CD4 counts $<100$ cells/L [68-70]; however, in young children it has poor diagnostic accuracy [71].

\section{Mycobacterial culture}

Mycobacterial cultures have the highest sensitivity and specificity for bacteriological confirmation of intrathoracic $\mathrm{TB}$ in children. The limits of detection of liquid and solid media are approximately $10-100 \mathrm{CFU} / \mathrm{mL}$ and 50-150 CFU/mL, respectively (versus $100-150 \mathrm{CFU} / \mathrm{mL}$ for RT-PCR or $1000-10,000 \mathrm{CFU} / \mathrm{mL}$ for fluorescent LED microscopy) [72]. In most prospective studies of children with a clinical diagnosis of probable pulmonary $\mathrm{TB}$, cultures of respiratory specimens are positive in 10$20 \%$ of cases. Studies reporting higher rates (i.e. $>30 \%$ ) of culture confirmation are often retrospective and include only children who are hospitalized (probably have more severe disease and better specimen collection strategies) or diagnosed following passive case finding [73]. For definitive species identification following growth in mycobacterial culture, the following methods may be utilized: (i) phenotypic analysis; (ii) antigen tests; (iii) molecular tests such as nucleic acid hybridization probes, matrix-assisted laser desorption/ionization timeof-flight mass spectrometry, and DNA sequencing.

\section{Histopathology}

Histopathological studies should be considered in intrathoracic clinical syndromes compatible with either TB disease or malignancy, especially when bacteriological tests fail to confirm an infectious etiology. Potentially useful tissues to biopsy include lymph nodes, pleura, pericardium and lung. Findings suggestive of $\mathrm{TB}$ are numerous granulomas in various developmental stages, some with central caseous necrosis [74]. However, granulomatous inflammation is not sufficiently specific to diagnose TB and differential diagnoses include bacterial (e.g. NTM, nocardiosis), fungal (e.g. histoplasmosis, coccidioidomycosis), helminthic (e.g. schistosomiasis) and, protozoal (e.g. toxoplasmosis) infections, autoimmune diseases (e.g. granulomatosis with polyangiitis), idiopathic etiologies (e.g. sarcoidosis), and foreign bodies. 


\section{Excluding alternative diagnoses}

In infants and children, the clinical diagnosis of intrathoracic $\mathrm{TB}$ is not always certain, as other disorders can present with similar clinical, radiological, and laboratory abnormalities, or may be present concomitantly. Chronic cough, failure to thrive and prolonged fever for example, have multiple etiologies (Additional file 1: Table S1). It may be possible to exclude some differential diagnoses by using sensitive diagnostic tests or if the child fails a diagnostic-therapeutic trial (i.e., no sustained improvement with appropriate empiric therapy) [75]. Examples of the latter include antibiotics for possible pneumonia, antimalarial agents for fever from presumed malaria, and nutritional support for failure to thrive from suspected under-nutrition. Excluding alternative diagnoses provides further support for a clinical diagnosis of TB disease.

\section{STEP 3: Screening for risk factors for progression to TB disease}

Identifying risk factors for progression from $\mathrm{TB}$ infection to disease (Additional file 1: Textbox 2) is important when intrathoracic TB (both pulmonary and extrapulmonary) is suspected. If these are present, this should hasten the diagnostic evaluation; expedite TB treatment (beginning immediately after collecting specimens for microbiological studies) if there are sufficient findings for a presumptive TB diagnosis; and guide preventive therapy in children with TB exposure and infection.

\section{STEP 4: Follow-up evaluation to further support or exclude TB as the etiology}

In very young or immunocompromised children, intrathoracic TB can present acutely; however, in otherwise immunocompetent children, it usually presents as a subacute or chronic illness. In the early stages, there may be insufficient findings to make a presumptive diagnosis, and, even if culture confirmation is attained, this can take weeks. It is therefore critical to perform follow-up evaluations to reassess the patient, whether or not treatment has been initiated, by continuing to reassess steps 1 and 2. On follow-up evaluations, failure to thrive may become more apparent, respiratory symptoms emerge, chest radiography may reveal new or increasing abnormalities, immune-based tests (TST/IGRA) may become positive, and $M$. tuberculosis is detected in respiratory specimens. As most (>90\%) children develop disease within the first 12-months of their primary infection, periodic reassessment during the first year of their infection being diagnosed is important.

\section{Structured diagnostic approaches}

The lack of a sensitive diagnostic test for intrathoracic TB means that many diagnostic approaches have been developed. Some are numerical (scoring systems), some hierarchical (case definitions for classification), and others binary (presence or absence of disease). Few have been validated against a gold standard [76]. Although some perform well in advanced disease where clinical and radiological findings are florid, they perform less well in patients with early or mild disease, in young children, and in immunocompromised patients, all of whom are challenging to diagnose [77]. Commonly used approaches have poor agreement with one another and yield highly variable case frequency results from differences in purpose (screening versus diagnosis; patient care versus research versus epidemiological surveillance); healthcare setting (community versus hospital); disease severity (mild versus severe); and prevalence of tuberculosis and/or HIV infection (low versus high) [13].

Clinical case definitions and management algorithms Clinical case definitions of TB exposure, infection, and presumptive and confirmed intrathoracic TB in children involve findings suggestive of $\mathrm{TB}$ disease (clinical, radiological); findings supportive of $\mathrm{TB}$ as the etiology (exposure, immune-based testing, mycobacterial testing, therapeutic response to TB treatment); and risk factors for progression to disease (Table 5). Figure 4 shows an algorithm providing recommendations for diagnosing and managing children with recent exposure to $\mathrm{TB}$ (active case finding), or with clinical and/or radiological findings suggestive of TB disease (passive case finding).

\section{TB exposure [ICD-10: Z20.1]}

TB exposure is defined as recent close contact with an adult or adolescent with infectious pulmonary TB (presumptive or bacteriologically confirmed), but without evidence of infection, and lacking clinical or radiological findings suggestive of disease. Not all contacts become infected with $\mathrm{TB}$, but most who do will demonstrate a positive T-cell-based test result within 2-10 weeks [43]. Therefore, in the initial evaluation of a child in a contact investigation, it is not always possible to determine whether a TB exposure has resulted in infection demonstrable by a T-cell-based test. Consequently, until a highly accurate test is developed for detecting an acute TB infection soon after it occurs, it is important to recognize "TB exposure" as a diagnosis, especially in child contacts with risk factors for progression to disease who will benefit from post-exposure prophylaxis. To become infected with $M$. tuberculosis, a susceptible child must inhale droplet nuclei (1-5 microns in diameter) from someone with infectious TB disease who is coughing. This usually involves close (i.e. shared air space in an enclosed environment) contact with an infectious case. Indeed, the longer the duration of exposure and closer the proximity to the case, the higher the risk for 
Table 5 Clinical case definitions and management of TB exposure, infection, and disease in children

\begin{tabular}{|c|c|c|c|c|c|c|}
\hline \multirow{4}{*}{$\begin{array}{l}\text { Diagnostic } \\
\text { classification }\end{array}$} & \multicolumn{2}{|l|}{ Step 1} & \multicolumn{3}{|l|}{ Step 2} & \multirow[t]{2}{*}{ Step 3} \\
\hline & \multicolumn{5}{|l|}{ Step 4} & \\
\hline & \multicolumn{2}{|c|}{$\begin{array}{l}\text { Findings suggestive } \\
\text { of TB disease? }\end{array}$} & \multicolumn{3}{|c|}{ Findings supportive of TB as the likely etiology? } & \multirow[t]{2}{*}{ Risk factors? (Management) } \\
\hline & Clinical $^{a}$ & $C X R^{b}$ & TB exposure (TST/IGRA) & M. tb detected & TB treatment response & \\
\hline TB exposure & None & Normal & $\begin{array}{l}\text { Yes } \\
\text { (Negative or unavailable) }\end{array}$ & No & Not applicable & $\begin{array}{l}\text { None (no PEP) } \\
\text { Yes (consider PEP) }\end{array}$ \\
\hline TB infection & None & $\begin{array}{l}\text { No signs suggestive } \\
\text { of TB disease } e^{c}\end{array}$ & Likely (Positive) & No & Not applicable & $\begin{array}{l}\text { None (consider LTBI treatment) } \\
\text { Yes (provide LTBI treatment) }\end{array}$ \\
\hline Presumptive TB & \multicolumn{2}{|c|}{$\begin{array}{l}\text { Clinical findings }{ }^{\mathrm{d}} \\
\text { and/or radiological findings } \\
\text { compatible with TB disease }\end{array}$} & $\begin{array}{l}\text { Likely } \\
\text { (Positive, may be } \\
\text { false negative) }\end{array}$ & No & Yes & Not applicable (TB treatment) \\
\hline Confirmed TB & & & $\begin{array}{l}\text { Likely } \\
\text { (Positive, may } \\
\text { be false negative) }\end{array}$ & Yes & Yes & Not applicable (TB treatment) \\
\hline
\end{tabular}

Adapted from C.M. Perez-Velez. Diagnosis of Intrathoracic Tuberculosis in Children. In: Handbook of Child and Adolescent Tuberculosis (p. 168), J.R. Starke and P.R. Donald (Eds.), 2016, New York, NY: Oxford University Press. Copyright by Oxford University Press [15]. Adapted with permission

Dx diagnostic, IGRA interferon-gamma release assay, NAAT nucleic acid amplification test, PEP post-exposure prophylaxis, TB tuberculosis, TST tuberculin skin test, $L T B I$ latent TB infection

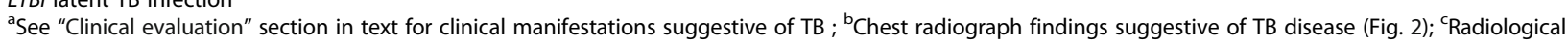
findings suggestive of inactive TB in a healthy child without symptoms or physical signs compatible with TB include (a) non-enlarged, homogenously calcified regional (parahilar/mediastinal or peripheral) lymph nodes; (b) calcified nodules with round borders in the lung parenchyma; (c) fibrotic scar or discrete linear opacity in the lung parenchyma ( \pm : calcifications within the lesion; or, volume lost, or retraction); and (d) pleural scarring (thickening or calcification). Compare

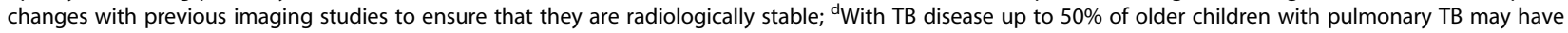
a normal physical exam

transmission. It is thus important to have a high index of suspicion for possible TB infection and to screen for risk factors (Additional file 1: Textbox 2).

\section{TB infection [ICD-10: R76.11 (by TST); R76.12 (by IGRA)]}

TB infection is defined clinically as an infection with any species of the $M$. tuberculosis complex, demonstrated by a positive T-cell-based test (TST and/or IGRA) result, without clinical manifestations or radiological abnormalities consistent with active TB. In a healthy child without symptoms or physical signs compatible with active TB, the following chest imaging findings-when shown to be radiologically stable (i.e., without changes compared to a previous imaging study within the past 4-6 months) - are generally considered indicative of previous TB disease that is currently inactive: (i) non-enlarged, homogeneously calcified regional (parahilar/mediastinal or peripheral) lymph nodes; (ii) calcified nodules with round borders in the lung parenchyma; (iii) fibrotic scar or discrete linear opacity in the lung parenchyma (with or without calcifications within the lesion; or, with or without volume loss, or retraction); and (iv) pleural scarring (thickening or calcification).

TB disease: clinical syndromes of intrathoracic TB [ICD-10: A15.X]

Intrathoracic TB can affect lung parenchyma, the airways, regional lymph nodes, pleura, and pericardium, while more than one organ may be involved concomitantly. The differential diagnosis of intrathoracic TB is broad, and making a syndromic diagnosis based on clinical, radiological, laboratory, and endoscopic (when indicated) findings helps narrow the list.

\section{Intrathoracic lymph node disease}

Infection and subsequent inflammation of intrathoracic lymph nodes is the pathophysiologic mechanism that determines most of the clinical and radiological findings of intrathoracic TB in children. Many of the radiological patterns in pediatric intrathoracic TB are characterized by intrathoracic lymph node involvement out of proportion to that of the lung parenchyma. Because radiographic density of lymph nodes is similar to that of the heart and consolidated lung, the exact extent of lymph node involvement may be difficult to discriminate on plain radiographs. Their presence is sometimes suggested when the airways are narrowed or displaced. However, chest CT scans can clearly reveal lymph node abnormalities not evident on plain radiography.

Children with isolated, uncomplicated non-calcified, intrathoracic lymphadenopathy are frequently asymptomatic. They are most often found during contact investigations or screening of children with high-risk factors for TB exposure. This radiological pattern may exist in a relatively early state (e.g. subclinical disease) of intrathoracic TB. Chest radiography may reveal one or more enlarged lymph nodes, most often in the right hilum. Subcarinal involvement leads to a splaying of the origins of the two main bronchi. While chest CT scans in these children may find 


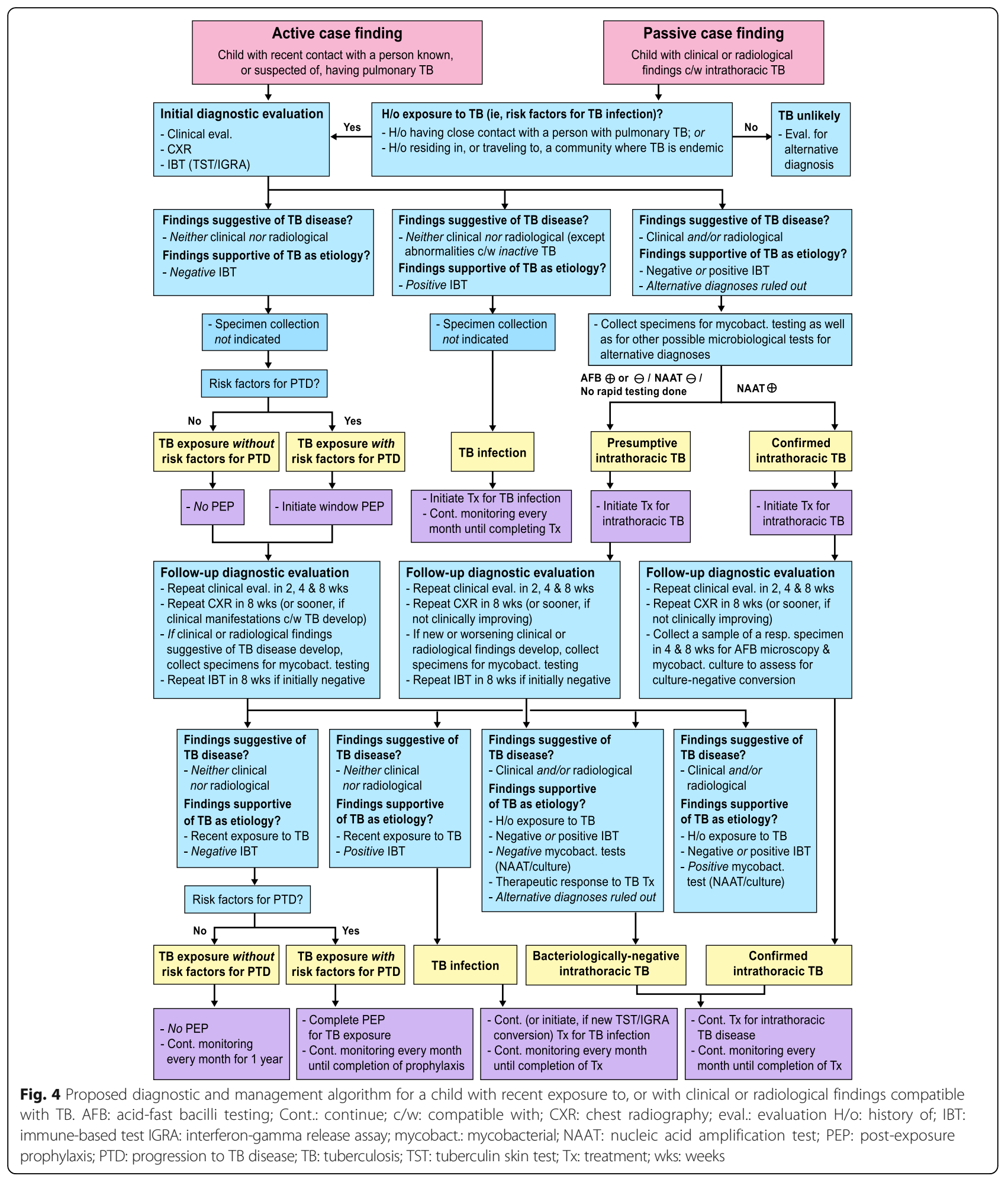

lung parenchymal abnormalities undetectable by plain chest radiography, this investigation is not indicated if they are completely asymptomatic.

Lymph node enlargement, occurring mostly in children aged $<5$ years, may progress to tracheal or bronchial compression. If complete, this leads to lobar collapse, or if partial to a ball-valve effect causing airtrapping and hyperinflation. Enlarged paratracheal nodes can cause partial tracheal obstruction and stridor. Symptoms vary with the degree of airway compression, from 
asymptomatic to persistent cough, wheeze or stridor; dyspnea and respiratory distress from extensive atelectasis; or hyperinflation created by pressure from the enlarged lymph nodes on adjacent structures. Chest radiography (especially high-kilovoltage radiography) and CT scans may demonstrate severe narrowing of a bronchus leading to either collapse or hyperinflation, most commonly of the right upper or middle lobes, or the left upper lobe.

\section{Tracheobronchial disease}

Endotracheal and endobronchial disease most often results from bronchogenic spread of TB after a diseased lymph node erodes into the airway, most commonly the left or right main bronchus and bronchus intermedius [24, 28]. Disease may be diffuse or localized with visible granulation tissue [78]. Damaged bronchi may dilate (bronchiectasis) or develop bronchostenosis [79]. Tracheobronchial disease can have an acute, insidious, or delayed onset, with symptoms or physical signs of airway obstruction that depend on the location and severity, including persistent cough, rhonchi, wheeze, stridor, and/or dyspnea. Chest radiography is not sensitive in detecting tracheobronchial disease, unless it is severe or has an associated fibronodular appearance in the lung parenchyma. Bronchiolar disease is revealed on CT scans and may appear as a tree-in-bud pattern or as centrilobular nodules consisting of dilated bronchioles that are thick-walled and filled with mucus. Bronchiectasis is also more easily noted on CT scans, which may show bronchial dilatation and wall-thickening. Bronchoscopy may demonstrate abnormalities suggestive of tracheobronchial disease, including hyperemia, edema, ulcers, masses, stenosis, granulation tissue or caseous lesions [80, 81].

\section{Parenchymal disease}

If inhaled M. tuberculosis bacilli are not destroyed immediately by the innate immune response, a small parenchymal focus of infection (primary/Ghon focus) may develop and drain via local lymphatic vessels to regional lymph nodes. Most nodular TB lung disease in children resolves spontaneously and is identified only by radiographic screening during contact investigations. Multiple, focal pulmonary nodules may be seen on chest imaging in the early stages of a TB bronchopneumonia. A child with a solitary pulmonary nodule, with or without associated lymphadenopathy, is most often asymptomatic. Chest radiography may reveal isolated lung opacity with enlarged ipsilateral thoracic lymph nodes, known as a primary/Ghon complex. When lymph node lesions are calcified, it is a Ranke complex. Chest CT scans are more sensitive at detecting small ill-defined airspace nodules that tend to coalesce in some parts, but are different from the discrete, sharply defined micronodules seen in miliary disease.
When the primary infection is poorly contained, mycobacteria replicate and the initial lesion may enlarge (lobar pneumonia). Hilar lymph nodes may also enlarge and sometimes compress or infiltrate contiguous bronchi, most commonly the right or left main bronchus, or bronchus intermedius [24]. If a necrotic hilar lymph node erupts into a bronchus, endobronchial spread leads to patchy or multifocal consolidation of the respective lobe (bronchopneumonia). When enlarged hilar lymph nodes are also compressing the bronchus, the endobronchial spread may cause distal expansion and dense consolidation of the entire lobe (expansile pneumonia) displacing the trachea, bowing the fissures and forming focal cavities. Cavities are uncommon in children, occurring predominantly in infants with extensive, uncontained disease or in adolescents with "adult-type" disease. Chest radiography and CT scans may reveal an oval-shaped lucency that is either isolated or within a consolidation or nodule, with walls that may be either thin or thick. In older children and adolescents there may be multiple cavities, located typically in the apical segments of the upper or lower lobes [9].

\section{Pleural disease}

TB pleural effusions typically occur 3-6 months after a primary infection and are usually unilateral, mostly resulting from a delayed-type hypersensitivity reaction to $M$. $t u$ berculosis antigens that leaked into the pleural space from a subpleural primary focus. Pleural thickening is a common component of the primary complex, but it rarely leads to a significant effusion. Large effusions are seen more often in older children (age $>5$ years) and adolescents. The child most often presents with pleuritic chest pain (58\%), cough (80\%) and fever (67\%) [82]. Chest radiography will reveal a homogeneously opacified fluid level, with pulmonary parenchymal abnormalities (usually consolidation) and intrathoracic lymphadenopathy often becoming visible post-drainage [21]. Chest ultrasonography is useful in determining the nature and quantity of the effusion and detecting early loculations and septations. Chest CT scans are useful in cases with complicated pleural effusion, detecting associated parenchymal lesions and intrathoracic lymphadenopathy, and differentiating between pleural thickening and a chronic loculated effusion or empyema. TB pleural fluids are most often exudative with lymphocytic pleocytosis. Because of its protein-rich nature, care must be taken to not remove too much pleural fluid in a severely malnourished child because this can acutely worsen the child's oncotic pressure. TB empyema has also been described [83], where pleural fluid is purulent [84]. Chylothorax is a rare type of pleural effusion resulting from disruption or obstruction of the thoracic 
duct (or its tributaries), leading to lymphatic fluid (chyle) leakage into the pleural space. The pleural fluid typically has a milky white appearance, and is predominantly lymphocytic with elevated levels of triglycerides $(>1.2 \mathrm{mmol} / \mathrm{L})$ [85].

\section{Pericardial disease}

TB is one of the most common causes of pericardial effusion in children in TB-endemic countries, and approximately $1-4 \%$ of children with TB develop pericarditis [86]. It has three main presentations: pericardial effusion (the most common), constrictive pericarditis, and a combination known as effusive-constrictive disease. It most frequently occurs after an infected contiguous subcarinal lymph node infiltrates the pericardium. It can also arise from lymphohematogenous dissemination of $M$. tuberculosis. HIV infection predisposes a patient to such disseminated disease, and is associated with greater severity of pericardial TB [87]. Children with TB pericarditis usually present with symptoms and signs of heart failure, including persistent cough (70\%), dyspnea (77\%), chest pain (30\%), hepatomegaly (77\%), elevated jugular venous pressure (7\%), soft heart sounds, and a pericardial friction rub (18\%), in addition to fever (52\%), night sweats, failure to thrive (36\%), fatigue, and malaise [88]. Chest radiography typically reveals cardiomegaly with a globular heart silhouette (91\%). Echocardiography is the most sensitive study to confirm a pericardial effusion, and may reveal associated mediastinal lymphadenopathy or other complications.

\section{Disseminated/miliary disease}

Miliary lung disease results from a TB lesion infiltrating into a blood vessel, leading to hematogenous dissemination [89]. The temporal pattern of miliary disease is usually acute, but it can also present with a delayed onset. Pulmonary involvement and respiratory symptoms occur relatively late in the disease. Given the multisystem involvement, presenting symptoms may include cough (72\%), dyspnea, diarrhea and vomiting (33\%), irritability, headache, convulsions, hepatomegaly (82\%), splenomegaly (54\%), lymphadenopathy (46\%), fever (39\%), chills, loss of appetite and failure to thrive (40\%), fatigue, generalized weakness, decreased activity, and malaise. The main complication is TB meningitis [89]. Chest radiography may reveal innumerable rounded micronodules ( $\leq 3 \mathrm{~mm}$ in diameter) scattered diffusely throughout both lungs, but in the initial stages of disseminated disease the radiological abnormalities may not be apparent $(9 \%)[79,89]$. Often these nodules are best seen on the lateral projection of the chest radiograph in the retrocardiac area.

\section{Conclusions}

Using currently available tools, a systematic diagnostic approach to the child with recent exposure to, or with clinical or radiological findings compatible with, TB can allow the clinician to classify most patients into one of the major diagnostic categories of TB exposure, infection, or disease. In cases of TB exposure and infection, identifying risk factors for progression to disease helps hasten diagnostic evaluation and initiating appropriate prophylaxis or treatment when indicated.

\section{Additional file}

Additional file 1: Table S1. Differential diagnosis of chronic cough in children. Table S2. Nucleic acid amplification tests for detecting Mycobacterium tuberculosis complex and genes encoding targets of mutations conferring drug resistance. Table S3. Differential diagnosis of clinical-radiological syndromes associated with intrathoracic TB in children. Textbox 1. Spectrum of possible organ involvement in TB disease. Textbox 2. Risk factors for TB infection in children. (PDF 617 kb)

\section{Abbreviations}

ADA: Adenosine deaminase; AFB: Acid-fast bacilli; BCG: Bacille Calmette-Guerin; CFU: Colony-forming unit; CT: Computed tomography; DNA: Deoxyribonucleic acid; HIV: Human immunodeficiency virus; ICD-10: International statistical classification of diseases and Related health problems, 10th revision; IGRA: Interferon-gamma release assay; LDH: Lactate dehydrogenase; LED: Light-emitting diode; LF-LAM: Lateral flow lipoarabinomannan; LPA: Line probe assay; M.: Mycobacterium; MDR: Multi-drug-resistant; NAAT: Nucleic acid amplification test; NTM: Nontuberculous mycobacteria; PPD: Purified protein derivative; RT-PCR: Real-time polymerase chain reaction; TB: Tuberculosis; TST: Tuberculin skin test

\section{Acknowledgements}

Sonia L. Villegas, MD, MPH, Charite - Medical University Berlin, Germany for her contributions to previous versions of the diagnostic and management algorithm for tuberculosis in children.

\section{Funding}

There were no funding sources for this review.

Availability of data and materials

Not applicable.

\section{Authors' contributions}

Both authors defined the scope of the review, searched the literature, assessed the evidence base, synthesized included studies, analyzed the findings, designed and drafted the manuscript and tables and figures, critically revised the manuscript, and approved the final version of the manuscript.

\section{Authors' information}

We decline this option, as we have nothing substantive to add to aid the reader's interpretation of the article, or to understand the standpoint of the authors].

\section{Consent for publication}

Not applicable (some figures and tables were adapted from figures and tables previously published by the authors [CMPV \& CLRP] with permission from the publishers).

\section{Competing interests}

The authors declare that they have no competing interests.

Ethics approval and consent to participate Not applicable. 


\section{Author details}

'Division of Pediatric Pulmonology, Department of Pediatrics, Faculty of Medicine, University of Antioquia, Medellin, Antioquia, Colombia. ${ }^{2}$ Grupo Tuberculosis Valle-Colorado (GTVC), Medellin, Antioquia, Colombia. ${ }^{3}$ Tuberculosis Clinic, Pima County Health Department, Tucson, AZ, USA. ${ }^{4}$ Division of Infectious Diseases, College of Medicine, University of Arizona, Tucson, AZ, USA. ${ }^{5}$ College of Medicine, University of Arizona, 1501 North Campbell Avenue, P.O. Box 24503985724 Tucson, AZ, USA.

\section{Received: 20 October 2016 Accepted: 3 November 2016}

\section{Published online: 24 November 2016}

\section{References}

1. Cruz AT, Starke JR. Clinical manifestations of tuberculosis in children. Paediatr Respir Rev. 2007:8:107-17. PMID:17574154. http://dx.doi.org/10. 1016/j.prrv.2007.04.008

2. Marais BJ, Graham SM. Childhood tuberculosis: a roadmap towards zero deaths. J Paediatr Child Health. 2016;52:258-61. PMID:24923706, http://dx. doi.org/10.1111/jpc.12647.

3. Young D, Stark J, Kirschner D. Systems biology of persistent infection: tuberculosis as a case study. Nat Rev Microbiol. 2008;6:520-8. PMID: 18536727, http://dx.doi.org/10.1038/nrmicro1919.

4. Barry 3rd CE, Boshoff HI, Dartois V, Dick T, Ehrt S, Flynn J, et al. The spectrum of latent tuberculosis: rethinking the biology and intervention strategies. Nat Rev Microbiol. 2009;7:845-55. PMID:19855401.

5. Young DB, Gideon HP, Wilkinson RJ. Eliminating latent tuberculosis. Trends Microbiol. 2009;17:183-8. PMID:19375916. http://dx.doi.org/10. 1016/j.tim.2009.02.005.

6. Deffur A, Mulder NJ, Wilkinson RJ. Co-infection with Mycobacterium tuberculosis and human immunodeficiency virus: an overview and motivation for systems approaches. Pathog Dis. 2013;69(2):101-13.

7. Salgame P, Geadas C, Collins L, Jones-López E, Ellner JJ. Latent tuberculosis infection-revisiting and revising concepts. Tuberculosis (Edinb). 2015;95: 373-84. PMID:26038289. http://dx.doi.org/10.1016/j.tube.2015.04.003.

8. Marais BJ, Gie RP, Schaaf HS, Hesseling AC, Enarson DA, Beyers N. The spectrum of disease in children treated for tuberculosis in a highly endemic area. Int J Tuberc Lung Dis. 2006;10:732-8. PMID:16848333.

9. Marais BJ, Gie RP, Hesseling AH, Beyers N. Adult-type pulmonary tuberculosis in children 10-14 years of age. Pediatr Infect Dis J. 2005;24: 743-4. PMID:16094237. http://dx.doi.org/10.1097/01.inf.0000173305.04212.09.

10. Wiseman CA, Gie RP, Starke JR, Schaaf HS, Donald PR, Cotton MF, et al. A proposed comprehensive classification of tuberculosis disease severity in children. Pediatr Infect Dis J. 2012;31:347-52. PMID:22315002. http://dx.doi. org/10.1097/NF.0b013e318243e27b.

11. O'Garra A, Redford PS, McNab FW, Bloom Cl, Wilkinson RJ, Berry MP. The immune response in tuberculosis. Annu Rev Immunol. 2013;31:475-527. PMID:23516984. http://dx,doi.org/10.1146/annurev-immunol-032712-095939.

12. Achkar JM, Jenny-Avital ER. Incipient and subclinical tuberculosis: defining early disease states in the context of host immune response. J Infect Dis. 2011;204 Suppl 4:S1179-86. PMID:21996700. http://dx.doi.org/ 10.1093/infdis/jir451.

13. Hatherill M, Hanslo M, Hawkridge T, Little F, Workman L, Mahomed $H$, et al. Structured approaches for the screening and diagnosis of childhood tuberculosis in a high prevalence region of South Africa. Bull World Health Organ. 2010;88:312-20. PMID:20431796. http://dx.doi.org/ 10.2471/BLT.09.062893.

14. Graham SM, Ahmed T, Amanullah F, Browning R, Cardenas V, Casenghi M, et al. Evaluation of tuberculosis diagnostics in children: 1. Proposed clinical case definitions for classification of intrathoracic tuberculosis disease. Consensus from an expert panel. J Infect Dis. 2012;205 Suppl 2:S199-208. PMID:22448023. http://dx.doi.org/10.1093/infdis/jis008.

15. Perez-Velez C. Diagnosis of intrathoracic tuberculosis in children. In: Starke JR, Donald PR, editors. Handbook of child and adolescent tuberculosis. New York: Oxford; 2016. p. 147-76.

16. Marais BJ, Gie RP, Hesseling AC, Schaaf HS, Lombard C, Enarson DA, et al. A refined symptom-based approach to diagnose pulmonary tuberculosis in children. Pediatrics. 2006;1 18:e1350-9. PMID:17079536. http://dx.doi.org/10. 1542/peds.2006-0519.

17. Hossain MM, Norazmi MN. Pattern recognition receptors and cytokines in Mycobacterium tuberculosis infection-the double-edged sword? BioMed Res Int. 2013;2013:179174.
18. Boulware DR, Callens S, Pahwa S. Pediatric HIV immune reconstitution inflammatory syndrome. Curr Opin HIV AIDS. 2008;3:461-7. PMID:19373006. http://dx.doi.org/10.1097/COH.0b013e3282fe9693.

19. Mohapatra PR, Janmeja AK. Tuberculous lymphadenitis. J Assoc Physicians India. 2009;57:585-90. PMID:20209720.

20. Marais BJ, Gie RP, Schaaf HS, Starke JR, Hesseling AC, Donald PR, et al. A proposed radiological classification of childhood intra-thoracic tuberculosis. Pediatr Radiol. 2004;34:886-94. PMID:15300340. http://dx.doi.org/10.1007/ s00247-004-1238-0.

21. Perez-Velez CM, Marais BJ. Tuberculosis in children. N Engl J Med. 2012;367: 348-61. PMID:22830465. http://dx.doi.org/10.1056/NEJMra1008049.

22. Smuts NA, Beyers N, Gie RP, Schaaf HS, Talent JM, Nel E, et al. Value of the lateral chest radiograph in tuberculosis in children. Pediatr Radiol. 1994;24:478-80. PMID:7885777, http://dx.doi.org/10.1007/BF02015003.

23. Andronikou S, Van der Merwe DJ, Goussard P, Gie RP, Tomazos N. Usefulness of lateral radiographs for detecting tuberculous lymphadenopathy in children-confirmation using sagittal $\mathrm{CT}$ reconstruction with multiplanar cross-referencing. South Afr J Radiol. 2012;16:87-92. http://dx.doi.org/10.4102/sajr.v16i3.288.

24. Andronikou S, Joseph E, Lucas S, Brachmeyer S, Du Toit G, Zar H, et al. CT scanning for the detection of tuberculous mediastinal and hilar lymphadenopathy in children. Pediatr Radiol. 2004;34:232-6. PMID:14710313. http://dx.doi.org/10.1007/s00247-003-1117-0.

25. Kim WS, Moon WK, Kim IO, Lee HJ, Im JG, Yeon KM, et al. Pulmonary tuberculosis in children: evaluation with CT. AJR Am J Roentgenol. 1997;168: 1005-9. PMID:9124105. http://dx.doi.org/10.2214/ajr.168.4.9124105.

26. Daltro P, Nunez-Santos E, Laya B. Pediatric tuberculosis. In: Garcia-Peña P, Guillerman R, editors. Pediatric chest imaging. 3rd ed. Berlin Heidelberg: Springer; 2014. p. 285-303.

27. WHO. Guidance for national tuberculosis programmes on the management of tuberculosis in children. Geneva: World Health Organization; 2014.

28. Goussard P, Gie R. The role of bronchoscopy in the diagnosis and management of pediatric pulmonary tuberculosis. Expert Rev Respir Med. 2014;8:101-9. PMID:24378192. http://dx.doi.org/10.1586/17476348.2013.863712.

29. Wessels G, Schaaf HS, Beyers N, Gie RP, Nel E, Donald PR. Haematological abnormalities in children with tuberculosis. J Trop Pediatr. 1999;45:307-10. PMID:10584477. http://dx.doi.org/10.1093/tropej/45.5.307.

30. Rasmussen TA, Søgaard OS, Camara C, Andersen PL, Wejse C. Serum procalcitonin in pulmonary tuberculosis [i.]. Int J Tuberc Lung Dis. 2011;15:251-6. PMID:21219690

31. Herlina M, Nataprawira HM, Garna H. Association of serum C-reactive protein and leptin levels with wasting in childhood tuberculosis. Singapore Med J. 2011;52:446-50. PMID:21731999.

32. Schaaf $H S$, Michaelis IA, Richardson M, Booysen CN, Gie RP, Warren R, et al. Adult-to-child transmission of tuberculosis: household or community contact? Int J Tuberc Lung Dis. 2003;7:426-31. PMID:12757042.

33. Mack U, Migliori GB, Sester M, Rieder HL, Ehlers S, Goletti D, et al. C. Lange; TBNET. LTBI: latent tuberculosis infection or lasting immune responses to $M$. tuberculosis? A TBNET consensus statement. Eur Respir J. 2009;33:956-73. PMID:19407047. http://dx.doi.org/10.1183/09031936.00120908.

34. Perez-Stable EJ, Slutkin G. A demonstration of lack of variability among six tuberculin skin test readers. Am J Public Health. 1985;75:1341-3. PMID: 4051078. http://dx.doi.org/10.2105/AJPH.75.11.1341.

35. van Zyl-Smit RN, Zwerling A, Dheda K, Pai M. Within-subject variability of interferon-g assay results for tuberculosis and boosting effect of tuberculin skin testing: a systematic review. PLoS ONE. 2009;4:e8517. PMID:20041113. http://dx.doi.org/10.1371/journal.pone.0008517.

36. Trajman A, Steffen RE, Menzies D. Interferon-gamma release assays versus tuberculin skin testing for the diagnosis of latent tuberculosis infection: an overview of the evidence. Pulmonary medicine. 2013;2013:601737.

37. Farhat M, Greenaway C, Pai M, Menzies D. False-positive tuberculin skin tests: what is the absolute effect of BCG and non-tuberculous mycobacteria? Int J Tuberc Lung Dis. 2006;10:1192-204. PMID:17131776.

38. Pai M, Zwerling A, Menzies D. Systematic review: T-cell-based assays for the diagnosis of latent tuberculosis infection: an update. Ann Intern Med. 2008;149:177-84. PMID:18593687. http://dx.doi.org/10.7326/00034819-149-3-200808050-00241.

39. Dheda K, van Zyl-Smit RN, Sechi LA, Badri M, Meldau R, Meldau S, et al. Utility of quantitative T-cell responses versus unstimulated interferongamma for the diagnosis of pleural tuberculosis. Eur Respir J. 2009;34:111826. PMID:19386693. http://dx.doi.org/10.1183/09031936.00005309. 
40. Chiang SS, Swanson DS, Starke JR. New diagnostics for childhood tuberculosis. Infect Dis Clin North Am. 2015;29:477-502. PMID:26188605. http://dx.doi.org/10.1016/j.idc.2015.05.011.

41. Metcalfe JZ, Everett CK, Steingart KR, Cattamanchi A, Huang L, Hopewell PC, et al. Interferon- $\gamma$ release assays for active pulmonary tuberculosis diagnosis in adults in low- and middle-income countries: systematic review and meta-analysis. J Infect Dis. 2011;204 Suppl 4:S1120-9. PMID:21996694, http://dx.doi.org/10.1093/infdis/jir410.

42. Adetifa IM, Ota MO, Jeffries DJ, Hammond A, Lugos MD, Donkor S, et al. Commercial interferon gamma release assays compared to the tuberculin skin test for diagnosis of latent Mycobacterium tuberculosis infection in childhood contacts in the Gambia. Pediatr Infect Dis J. 2010;29:439-43. PMID:20068506, http://dx.doi.org/10.1097/INF.0b013e3181cb45da

43. Lalvani A, Millington KA. T cell-based diagnosis of childhood tuberculosis infection. Curr Opin Infect Dis. 2007;20:264-71. PMID:17471036. http://dx.doi. org/10.1097/QCO.0b013e32813e3fd8.

44. Merino JM, Carpintero I, Alvarez T, Rodrigo J, Sánchez J, Coello JM. Tuberculous pleural effusion in children. Chest. 1999;115:26-30. PMID: 9925059. http://dx.doi.org/10.1378/chest.115.1.26.

45. Goto M, Noguchi Y, Koyama H, Hira K, Shimbo T, Fukui T. Diagnostic value of adenosine deaminase in tuberculous pleural effusion: a meta-analysis. Ann Clin Biochem. 2003;40:374-81. PMID:12880538. http://dx.doi.org/10. 1258/000456303766477011</jrn\&gt.

46. Roya-Pabon C. Especímenes respiratorios para el diagnóstico microbiológico de las infecciones respiratorias. In: Posada-Saldarriaga R, editor. Neumología pediátrica. Bogotá: Distribuna; 2016. p. 171-92

47. Warren JR, Bhattacharya M, De Almeida KN, Trakas K, Peterson LR. A minimum $5.0 \mathrm{ml}$ of sputum improves the sensitivity of acid-fast smear for Mycobacterium tuberculosis. Am J Respir Crit Care Med. 2000;161:1559-62. PMID:10806154. http://dx.doi.org/10.1164/ajrccm.161.5.9908063.

48. Mpagama SG, Mtabho C, Mwaigwisya S, Mleoh LJ, Boer IM, Heysell SK, et al. Comparison of overnight pooled and standard sputum collection method for patients with suspected pulmonary tuberculosis in northern Tanzania. Tuberc Res Treat. 2012;2012:128057.

49. Singh S, Singh A, Prajapati S, Kabra SK, Lodha R, Mukherjee A, et al. Delhi Pediatric TB study group Xpert MTB/RIF assay can be used on archived gastric aspirate and induced sputum samples for sensitive diagnosis of paediatric tuberculosis. BMC Microbiol. 2015;15:191. PMID:26420261. http://dx.doi.org/10.1186/s12866-015-0528-z.

50. Cruz AT, Merchant O, Zafar A, Starke JR. Tuberculosis exposure, infection and disease among children with medical comorbidities. Pediatr Infect Dis J. 2014; 33:885-8. PMID:24642517. http://dx.doi.org/10.1097/INF.0000000000000343.

51. Zar HJ, Workman L, Isaacs W, Munro J, Black F, Eley B, et al. Rapid molecular diagnosis of pulmonary tuberculosis in children using nasopharyngeal specimens. Clin Infect Dis. 2012;55:1088-95. PMID:22752518. http://dx.doi. org/10.1093/cid/cis598.

52. Abadco DL, Steiner P. Gastric lavage is better than bronchoalveolar lavage for isolation of Mycobacterium tuberculosis in childhood pulmonary tuberculosis. Pediatr Infect Dis J. 1992;11:735-8. PMID:1448314. http://dx.doi. org/10.1097/00006454-199209000-00013.

53. Somu N, Swaminathan S, Paramasivan CN, Vijayasekaran D, Chandrabhooshanam A, Vijayan VK, et al. Value of bronchoalveolar lavage and gastric lavage in the diagnosis of pulmonary tuberculosis in children. Tuber Lung Dis. 1995;76:295-9. PMID:7579310. http://dx.doi.org/10.1016/ S0962-8479(05)80027-9.

54. Chow F, Espiritu N, Gilman RH, Gutierrez R, Lopez S, Escombe AR, et al. La cuerda dulce-a tolerability and acceptability study of a novel approach to specimen collection for diagnosis of paediatric pulmonary tuberculosis. BMC Infect Dis. 2006;6:67. PMID:16595008. http://dx.doi.org/10.1186/1471-2334-6-67.

55. Perez-Velez C, Wilches-Luna E, Hernández-Sarmiento J, Casanova-Reynolds A, Hernandez N, Moreno-Ortega S, editors. Preliminary results of a comparative yield study of induced sputum, string test, and gastric aspirate for the microbiological diagnosis of pulmonary tuberculosis in children. New York: Amer Thoracic Soc; 2010. AMERICAN JOURNAL OF RESPIRATORY AND CRITICAL CARE MEDICINE.

56. Walters E, Gie RP, Hesseling AC, Friedrich SO, Diacon AH, Gie RP. Rapid diagnosis of pediatric intrathoracic tuberculosis from stool samples using the Xpert MTB/RIF assay: a pilot study. Pediatr Infect Dis J. 2012;31:1316. PMID:23188101. http://dx.doi.org/10.1097/INF.0b013e318266c21c.

57. Nicol MP, Spiers K, Workman L, Isaacs W, Munro J, Black F, et al. Xpert MTB/ RIF testing of stool samples for the diagnosis of pulmonary tuberculosis in children. Clin Infect Dis. 2013;57:e18-21. PMID:23580738. http://dx.doi.org/ 10.1093/cid/cit230.

58. Wright CA, Warren RM, Marais BJ. Fine needle aspiration biopsy: an undervalued diagnostic modality in paediatric mycobacterial disease. Int J Tuberc Lung Dis. 2009;13:1467-75. PMID:19919763.

59. Denkinger CM, Schumacher SG, Boehme CC, Dendukuri N, Pai M, Steingart KR. Xpert MTB/RIF assay for the diagnosis of extrapulmonary tuberculosis: a systematic review and meta-analysis. Eur Respir J. 2014;44:435-46. PMID: 24696113. http://dx.doi.org/10.1183/09031936.00007814.

60. J Clin Tuberc Other Mycobact Dis. 2016;4:33-43. http://dx.doi.org/10.1016/j. jctube.2016.05.005

61. Gómez PD, Torronteras SR, Caro MP, López BA, Macías MP, Andrés MA, et al. An Esp Pediatr. 2000;53:405-11. PMID:11141361. http://dx.doi.org/10.1016/ S1695-4033(00)78620-6.

62. Zar HJ, Hanslo D, Apolles P, Swingler G, Hussey G. Induced sputum versus gastric lavage for microbiological confirmation of pulmonary tuberculosis in infants and young children: a prospective study. Lancet. 2005;365:130-4. PMID:15639294. http://dx.doi.org/10.1016/S0140-6736(05)17702-2.

63. Laven GT. Diagnosis of tuberculosis in children using fluorescence microscopic examination of gastric washings. Am Rev Respir Dis. 1977;115:743-9. PMID:857714.

64. WHO. Automated real-time nucleic acid amplification technology for rapid and simultaneous detection of tuberculosis and rifampicin resistance: Xpert MTB/ RIF assay for the diagnosis of pulmonary and extrapulmonary TB in adults and children: policy update. Geneva: World Health Organization; 2013.

65. WHO. Molecular line probe assays for rapid screening of patients at risk of multidrug-resistant tuberculosis (MDR-TB). Geneva: World Health Organization; 2008.

66. WHO. The use of molecular line probe assay for the detection of resistance to second-line anti-tuberculosis drugs: expert group meeting report, Geneva, February 2013. Geneva: World Health Organization; 2013.

67. Sanchini A, Fiebig L, Drobniewski F, Haas W, Richter E, Katalinic-Jankovic V, et al. European reference laboratory network for TB members. Laboratory diagnosis of paediatric tuberculosis in the European Union/European Economic Area: analysis of routine laboratory data, 2007 to 2011. Euro Surveill. 2014;19. PMID: 24679723. http://dx.doi.org/10.2807/1560-7917.ES2014.19.11.20744.

68. Lawn SD, Kerkhoff AD, Vogt M, Wood R. High diagnostic yield of tuberculosis from screening urine samples from HIV-infected patients with advanced immunodeficiency using the Xpert MTB/RIF assay. J Acquir Immune Defic Syndr. 2012;60:289-94. PMID:22531759. http://dx.doi.org/10. 1097/QAl.0b013e318258c6af

69. Lawn SD, Dheda K, Kerkhoff AD, Peter JG, Dorman S, Boehme CC, et al. Determine TB-LAM lateral flow urine antigen assay for HIV-associated tuberculosis: recommendations on the design and reporting of clinical studies. BMC Infect Dis. 2013;13:407. PMID:24004840. http://dx.doi.org/10. 1186/1471-2334-13-407.

70. Mutetwa R, Boehme C, Dimairo M, Bandason T, Munyati SS, Mangwanya D, et al. Diagnostic accuracy of commercial urinary lipoarabinomannan detection in African tuberculosis suspects and patients. Int J Tuberc Lung Dis. 2009;13:1253-9. PMID:19793430.

71. Nicol MP, Allen V, Workman L, Isaacs W, Munro J, Pienaar S, et al. Urine lipoarabinomannan testing for diagnosis of pulmonary tuberculosis in children: a prospective study. Lancet Glob Health. 2014;2:e278-84. PMID: 24818083. http://dx.doi.org/10.1016/S2214-109X(14)70195-0.

72. Society AT. Diagnostic standards and classification of tuberculosis in adults and children. Am J Respir Crit Care Med. 2000;161:1376-95. PMID:10764337. http://dx.doi.org/10.1164/ajrccm.161.4.16141.

73. Marais BJ, Hesseling AC, Gie RP, Schaaf HS, Enarson DA, Beyers N. The bacteriologic yield in children with intrathoracic tuberculosis. Clin Infect Dis. 2006;42:e69-71. PMID:16575719. http://dx.doi.org/10.1086/502652.

74. Demers A, Whitelaw A, Eisenach K. Microbiology and pathology of tuberculosis. In: Starke J, Donald P, editors. Handbook of child and adolescent tuberculosis. New York: Oxford; 2016. p. 13-29.

75. Hamilton G. Emergency medicine: an approach to clinical problem-solving. Saunders; 1991.

76. Hesseling AC, Schaaf HS, Gie RP, Starke JR, Beyers N. A critical review of diagnostic approaches used in the diagnosis of childhood tuberculosis. Int J Tuberc Lung Dis. 2002;6:1038-45. PMID:12546110.

77. Graham SM. The use of diagnostic systems for tuberculosis in children. Indian J Pediatr. 2011;78:334-9. PMID:21165720. http://dx.doi.org/10.1007/ s12098-010-0307-7. 
78. de Blic J, Azevedo I, Burren CP, Le Bourgeois M, Lallemand D, Scheinmann P. The value of flexible bronchoscopy in childhood pulmonary tuberculosis. Chest. 1991; 100:688-92. PMID:1909618. http://dx.doi.org/10.1378/chest.100.3.688.

79. Marais BJ, Gie RP, Schaaf HS, Hesseling AC, Obihara CC, Starke JJ, et al. The natural history of childhood intra-thoracic tuberculosis: a critical review of literature from the pre-chemotherapy era. Int J Tuberc Lung Dis. 2004:8:392-402. PMID:15141729.

80. Chung HS, Lee JH. Bronchoscopic assessment of the evolution of endobronchial tuberculosis. Chest. 2000;117:385-92. PMID:10669679. http:// dx.doi.org/10.1378/chest.117.2.385.

81. Cakir E, Uyan ZS, Oktem S, Karakoc F, Ersu R, Karadag B, et al. Flexible bronchoscopy for diagnosis and follow up of childhood endobronchial tuberculosis. Pediatr Infect Dis J. 2008;27:783-7. PMID:18664928. http://dx. doi.org/10.1097/INF.0b013e318170fccc.

82. Cruz AT, Ong LT, Starke JR. Childhood pleural tuberculosis: a review of 45 cases. Pediatr Infect Dis J. 2009;28:981-4. PMID:19672211. http://dx.doi.org/ 10.1097/INF.0b013e3181a8568b.

83. Fischer GB, Andrade CF, Lima JB. Pleural tuberculosis in children Paediatr Respir Rev. 2011;12:27-30. PMID:21172672. http://dx.doi.org/10. 1016/j.prrv.2010.11.001.

84. Strnad L, Denkinger C, Pai M. Effusions from infections: tuberculosis. In: Light R, Gary Lee YC, editors. Textbook of pleural diseases, vol. 3rd. Boca Raton: CRC; 2016. p. 331-42.

85. Grobbelaar M, Andronikou S, Goussard P, Theron S, Mapukata A, George R. Chylothorax as a complication of pulmonary tuberculosis in children. Pediatr Radiol. 2008;38:224-6. PMID:17929008. http://dx.doi.org/ 10.1007/s00247-007-0634-7.

86. Weber S. Tuberculosis and pericarditis in children. Trop Doct. 1999;29:135-8. PMID:10448233.

87. Mayosi BM, Wiysonge CS, Ntsekhe M, Volmink JA, Gumedze F, Maartens G, et al. Clinical characteristics and initial management of patients with tuberculous pericarditis in the HIV era: the Investigation of the Management of Pericarditis in Africa (IMPI Africa) registry. BMC Infect Dis. 2006;6:2. PMID: 16396690. http://dx.doi.org/10.1186/1471-2334-6-2.

88. Hugo-Hamman CT, Scher H, De Moor MM. Tuberculous pericarditis in children: a review of 44 cases. Pediatr Infect Dis J. 1994;13:13-8. PMID: 8170726. http://dx.doi.org/10.1097/00006454-199401000-00004.

89. Hussey G, Chisholm T, Kibel M. Miliary tuberculosis in children: a review of 94 cases. Pediatr Infect Dis J. 1991;10:832-6. PMID:1749696. http://dx.doi. org/10.1097/00006454-199111000-00008.

90. Tebruegge M, Dutta B, Donath S, Ritz N, Forbes B, Camacho-Badilla K, et al. Mycobacteria-specific cytokine responses detect tuberculosis infection and distinguish latent from active tuberculosis. Am J Respir Crit Care Med. 2015; 192:485-99. PMID:26030187. http://dx.doi.org/10.1164/rccm.201501-00590C.

91. Ankrah AO, van der Werf TS, de Vries EF, Dierckx RA, Sathekge MM, Glaudemans AW. PET/CT imaging of Mycobacterium tuberculosis infection. Clin Transl Imaging. 2016;4:131-44. PMID:27077068. http://dx.doi.org/10. 1007/s40336-016-0164-0.

92. Alland D, Rowneki M, Smith L, Chakravorty S, Ryan J, Chancellor M, editors. Xpert MTB/RIF ultra: a new near-patient TB test with sensitivity equal to culture. 15th Annual Conference on Retroviruses and Opportunistic Infections Seattle, Washington; 2015.

93. Lessem E. The tuberculosis diagnostics pipeline. Pipeline Report. 2016:2016:129

94. Clifford V, Zufferey C, Street A, Denholm J, Tebruegge M, Curtis N. Cytokines for monitoring anti-tuberculous therapy: a systematic review. Tuberculosis (Edinb). 2015;95:217-28. PMID:25797612. http://dx.doi.org/10.1016/j.tube.2015.01.003.

95. Casanova JL. Severe infectious diseases of childhood as monogenic inborn errors of immunity. Proc Natl Acad Sci U S A. 2015;112:E7128-37. PMID:26621750.

\section{Submit your next manuscript to BioMed Central and we will help you at every step:}

- We accept pre-submission inquiries

- Our selector tool helps you to find the most relevant journal

- We provide round the clock customer support

- Convenient online submission

- Thorough peer review

- Inclusion in PubMed and all major indexing services

- Maximum visibility for your research

Submit your manuscript at www.biomedcentral.com/submit
Biomed Central 